\title{
Toward a General Mechanism of Electron Capture Dissociation
}

\author{
Erik A. Syrstad and František Tureček \\ Department of Chemistry, University of Washington, Seattle, Washington, USA
}

The effects of positive charge on the properties of ammonium and amide radicals were investigated by ab initio and density functional theory calculations with the goal of elucidating the energetics of electron capture dissociation (ECD) of multiply charged peptide ions. The electronic properties of the amide group in N-methylacetamide (NMA) are greatly affected by the presence of a remote charge in the form of a point charge, methylammonium, or guanidinium cations. The common effect of the remote charge is an increase of the electron affinity of the amide group, resulting in exothermic electron capture. The $\mathrm{N}-\mathrm{C}_{\alpha}$ bond dissociation and transition state energies in charge-stabilized NMA anions are $20-50 \mathrm{~kJ} \mathrm{~mol}^{-1}$ greater than in the hydrogen atom adduct. The zwitterions formed by electron capture have proton affinities that were calculated as $1030-1350 \mathrm{~kJ} \mathrm{~mol}^{-1}$, and are sufficiently basic for the amide carbonyl to exothermically abstract a proton from the ammonium, guanidinium and imidazolium groups in protonated lysine, arginine, and histidine residues, respectively. A new mechanism is proposed for ECD of multiply charged peptide and protein cations in which the electron enters a charge-stabilized electronic state delocalized over the amide group, which is a superbase that abstracts a proton from a sterically proximate amino acid residue to form a labile aminoketyl radical that dissociates by $\mathrm{N}-\mathrm{C}_{\alpha}$ bond cleavage. This mechanism explains the low selectivity of $\mathrm{N}-\mathrm{C}_{\alpha}$ bond dissociations induced by electron capture, and is applicable to dissociations of peptide ions in which the charge carriers are metal ions or quaternary ammonium groups. The new amide superbase and the previously proposed mechanisms of ECD can be uniformly viewed as being triggered by intramolecular proton transfer in charge-reduced amide cation-radicals. In contrast, remote charge affects $\mathrm{N}-\mathrm{H}$ bond dissociation in weakly bound ground electronic states of hypervalent ammonium radicals, as represented by methylammonium, $\mathrm{CH}_{3} \mathrm{NH}_{3}$, but has a negligible effect on the $\mathrm{N}-\mathrm{H}$ bond dissociation in the strongly bound excited electronic states. This refutes previous speculations that loss of "hot hydrogen" can occur from an excited state of an ammonium radical. (J Am Soc Mass Spectrom 2005, 16, 208-224) @ 2004 American Society for Mass Spectrometry

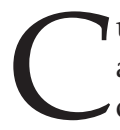
urrent methods of qualitative and quantitative analysis of proteins by mass spectrometry rely on specific dissociations of gas-phase ions that reveal the amino acid sequence [1]. Peptide and protein cations are typically produced by attachment of single or multiple protons or alkali metal cations to the analyte molecule, forming gas-phase ions that have closed electronic shells and carry one or more charges. Dissociations of such closed-shell ions, induced by collisional activation [2] or irradiation by an infrared laser [3], result in backbone dissociations yielding series of sequence-specific ions. In addition to dissociations of closed-shell cations, peptide and protein cation-radicals have recently been shown to undergo different types of dissociations that are often complementary to those of closed shell cations, and thus represent a useful tool for protein sequencing $[4,5]$. The most general method of

Published online December 16, 2004

Address reprint requests to Dr. F. Tureček, Department of Chemistry, University of Washington, Bagley Hall, Box 351700, Seattle, WA 98195-1700, USA. E-mail: turecek@chem.washington.edu producing peptide cation-radicals in the gas phase is by exposing multiply protonated peptides to low-energy electrons, which leads to exothermic ion-electron recombination [6]. The resulting peptide cation-radicals dissociate by a variety of reactions, namely, loss of $\mathrm{H}$ atoms, ammonia, and side chain fragments, cleavage of disulfide bonds, and, in particular, backbone cleavages. This electron capture dissociation (ECD) [7] has been shown to induce a moderate to high portion of backbone cleavages in peptide and protein ions. A mechanism has been proposed [8] to explain these peptide backbone cleavages, that considered electron attachment at one of the protonation sites, which is usually a lysine $\varepsilon$-ammonium group, an arginine guanidinium group, a histidine imidazolium ring, or an N-terminal ammonium group. Electron attachment to these cations forms radical intermediates that dissociate by hydrogen atom expulsion. The hydrogen atom is captured by the carbonyl group of a sterically proximate amide bond, yielding an aminoketyl intermediate that dissociates by cleavage of the adjacent $\mathrm{N}-\mathrm{C}_{\alpha}$ bond (Scheme 1).

The resulting fragments are an $\alpha$-amide radical at- 


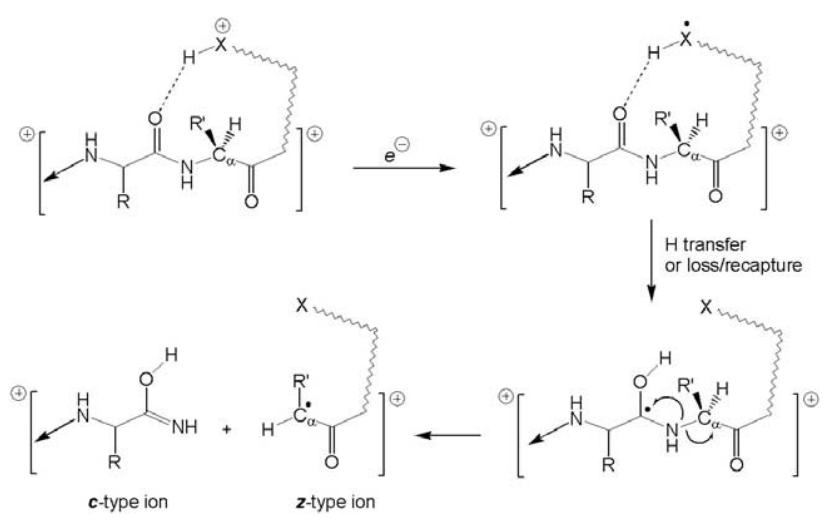

Scheme 1. The current ECD mechanism for $\mathrm{H}$ atom transfer and dissociation in internally-solvated peptide ions.

tached to the residues of the peptide C-terminus $(z$ series ions), and an enolimine attached to the residues of the N-terminus ( $c$-series ions). The $z$ and $c$ series are complementary by mass and can be observed in the mass spectrum if they carry a charge. In addition, ECD of multiply charged peptides produces ions that arise by consecutive or competitive dissociations of the side chains or within the peptide backbone [9].

The mechanism in Scheme $\mathbf{1}$ has been scrutinized by experimental and computational studies of model amide and peptide systems [10-16] These have shown that the isomerization of ammonium to aminoketyl radicals is $60-80 \mathrm{~kJ} \mathrm{~mol}^{-1}$ exothermic and can proceed as a two-step hydrogen elimination-recapture reaction or as a one-step hydrogen migration. Both the hydrogen atom elimination and migration have been shown to be very fast reactions in thermal peptide radicals, and the branching ratios for these two channels are affected by tunneling effects [13]. Recapture of a hydrogen atom by an amide group must overcome an energy barrier on the order of $50 \mathrm{~kJ} \mathrm{~mol}^{-1}$ and can occur at the oxygen or carbon atoms in neutral amides [10]. The aminoketyl radicals formed by hydrogen transfer to the amide carbonyl oxygen are weakly bound with respect to $\mathrm{N}-\mathrm{C}_{\alpha}$ bond cleavage, which is thermoneutral or exothermic in peptides and requires only a $30-50 \mathrm{~kJ} \mathrm{~mol}^{-1}$ energy barrier [14, 15].

One feature that distinguishes the computational model studies from ECD experiments is the presence of one or more charges in the cation-radicals produced by electron capture. The effects of charge have been addressed recently in several studies [14-17]. First, it was shown that the energy barrier for $\mathrm{N}-\mathrm{C}_{\alpha}$ bond cleavage is not dramatically affected by the presence of an adjacent charge [14]. However, charge has a large effect on the reaction exothermicity, because the incipient $c$ and $z$ fragments remain engaged in ion-molecule complexes that are $>100 \mathrm{~kJ} \mathrm{~mol}^{-1}$ more stable than the peptide cation-radical reactant [15]. In contrast, charge had only a small effect on the properties of ammonium radicals in model 1,2-diammonium systems that were calculated to undergo usual $\mathrm{N}-\mathrm{H}$ and $\mathrm{N}-\mathrm{C}$ bond dissociations whose energy barriers resembled those in neutral systems [16]. Simons and co-workers have recently examined by computations the effect of a point charge on electron capture by the disulfide bond in dimethyl disulfide [17]. They found that even a remote point charge lowered the energy of the $\mathrm{CH}_{3} \mathrm{SSCH}_{3}$ anion radical, such that it became a bound species which was prone to a highly exothermic dissociation of the $S-S$ bond. These results provided an explanation for the efficient $S-S$ bond cleavage upon ECD of model peptide systems where the charge was in the form of two quaternary ammonium groups that were kept far away from the disulfide bond, and did not generate hydrogen atoms upon electron capture [18].

A puzzling feature of ECD is the relatively low selectivity in $\mathrm{N}-\mathrm{C}_{\alpha}$ bond cleavages following single electron capture. The mechanism in Scheme $\mathbf{1}$ can be expected to work best when the charged group in the peptide ion is internally solvated by a backbone amide group, which is converted to the fragile aminoketyl radical by one-step hydrogen migration. Recent experimental evidence for model peptides suggests that the position of the dissociating $\mathrm{N}-\mathrm{C}_{\alpha}$ bond is affected by the peptide conformation. For example, ECD on doubly charged substance $\mathrm{P}$ ions that were cooled to $86 \mathrm{~K}$ resulted in only two backbone cleavages, as opposed to eight backbone cleavages in ions at $298 \mathrm{~K}$ [19]. However, it is not clear from these experiments if nonspecific ECD at room temperature takes place in a mixture of ion conformers, or if the charge-reduced ions undergo conformational transformations that allow hydrogen transfer to occur to different amide carbonyl groups.

The dissociation-recapture mechanism faces several problems that were reiterated recently [20]. One problem is that the cross sections for hydrogen atom capture by gas-phase peptide ions are low, as evidenced by the absence of addition or dissociation reactions when peptide ions were exposed to $\mathrm{H}$ atoms in an ICR cell [21]. This is corroborated by ab initio studies that showed that $\mathrm{H}$ atom additions to amide carbonyl groups have substantial energy barriers and are expected to be negligibly slow in thermal species for which transition state theory calculations give rate constants on the order of $10^{-18}$ molecule $\mathrm{cm}^{-3} \mathrm{~s}^{-1}$ [13]. The addition can possibly be facilitated with translationally hot hydrogen atoms that are produced by exothermic dissociation of ammonium radicals [13]. However, recent reaction dynamics calculations with a model system suggest that a short-lived complex of a translationally hot hydrogen atom and an amide bond has a very low probability for undergoing $\mathrm{N}-\mathrm{C}_{\alpha}$ bond cleavage, the main process being expulsion of the $\mathrm{H}$ atom [22].

A fundamental problem of the hot hydrogen atom mechanism is that an $\mathrm{H}$ atom addition to an amide carbonyl group is expected to occur at both oxygen and carbon atoms for which high-level ab initio calculations predict very similar activation energies [10, 11]. The 
latter would produce oxide radicals that can be expected to trigger dissociations leading to $a$ and $y$ type fragments, which are rarely observed in ECD. Furthermore, the small cross sections for $\mathrm{H}$ atom recapture by neutral amide groups would almost certainly disfavor addition if these groups are remote from or unsuitably oriented toward the source of the $\mathrm{H}$ atom.

O'Connor and coworkers have suggested that multiple cleavage sites can be produced by consecutive dissociations of radicals formed by an initial peptide bond cleavage [9c]. However, the energetics of such a dissociation cascade is unknown at present, and the proposed mechanisms await validation. Another suggestion has been advanced recently $[20,23]$ that considered electron capture in a high-lying Rydberg orbital of the peptide cation, followed by crossing to a dissociative electronic state. This mechanism is analogous to the direct model of dissociative recombination [24]. Interestingly, a recent theoretical study of a small hypervalent radical [25] concluded that dissociative recombination can rather be explained by an indirect mechanism [26] in which electron capture produces a vibrationally excited bound state.

In the present work we analyze the effects of charge on the properties and reactivities of radicals incorporating ammonium, guanidinium, and amide groups. The amide group is represented by $\mathrm{N}$-methylacetamide (NMA) that has been used as a model previously and the energetics of which have been studied by both experiment and high levels of theory [11]. We wish to show that a remote charge has a substantial effect on the stability and reactivity of an amide group following electron capture. A new mechanism is proposed that explains the dissociation of remote amide groups and the formation of $c$ and $z$ fragments upon ECD.

\section{Calculations}

Standard ab initio and density functional theory calculations were performed using the Gaussian 98 and Gaussian 03 suite of programs [27]. Geometries were optimized using Becke's hybrid functional (B3LYP) [28] with the 6-31 + G(d,p), 6-31 + + G(d,p), and 6-311 ++ $\mathrm{G}(2 \mathrm{~d}, \mathrm{p})$ basis sets. Optimized structures of NMA and related radicals that were calculated at similar levels of theory were taken from a previous study [11]. Background charge distributions were generated with fixed positive point charges at various orientations relative to independently optimized structures. Local minima were characterized by harmonic frequency analysis by having all real frequencies, and first-order saddle points were characterized by having one imaginary frequency. Charge and spin distributions were obtained from Natural Orbital Population analyses [29] that were performed with B3LYP using basis sets of increasing size, e.g., 6-31 + + G(d,p), 6-311 + + G(2d,p), 6-311 ++ $\mathrm{G}(3 \mathrm{df}, 2 \mathrm{pd})$, and aug-cc-pVTZ [30]. Improved energies were obtained from single-point calculations at several levels of theory. For select structures in the NMA system, composite G2(MP2) energies [31] were determined from MP2/6-311 + G(3df,2p) and quadratic configuration interaction calculations, QCISD(T)/6$311 G(d, p)$ [32]. For methylammonium, single-point energies were calculated by both B3-PMP2/6-311 ++ G(2d,p) [33] and using coupled clusters [34] with single, double, and perturbational triple excitations of valence electrons (CCSD(T)) [35] and the correlation-consistent basis set of triple- $\zeta$ quality with diffuse functions on all atoms (aug-cc-pVTZ) [30]. Spin-unrestricted calculations (UB3LYP, UMP2, UQCISD(T), and $\operatorname{UCCSD}(\mathrm{T})$ ) were used for open-shell systems. In the UB3LYP calculations, $\left\langle S^{2}>\right.$ operator expectation values ranged from $0.750-0.755$, indicating negligible spin contamination. However, $\left\langle S^{2}>\right.$ values in UMP2 and UQCISD(T) calculations ranged from 0.75 to 0.86 for transition states. Spin annihilation using Schlegel's projection method [36] (PMP2) reduced the $<S^{2}>$ values to $\leq 0.753$ for all structures.

Vertical excitation energies for excited electronic states were obtained by time-dependent density functional theory [37] calculations with UB3LYP using the 6-31 + + G(d,p), 6-311 + + G(d,p), 6-311 + + G(3df,2pd), and aug-cc-pVTZ basis sets, and along with oscillator strengths were used to calculate excited state radiative lifetimes. Excitation configurations and expansion coefficients were used to scale and mix the appropriate virtual orbitals for the generation of composite excited state molecular orbitals. The excited state energies showed a gradual compression, especially for higher states, when going from the $6-31++G(d, p)$ to the aug-cc-pVTZ basis set. The latter large basis set places two polarization plus one diffuse, $(2+1), d$ shells and $(1+1) f$ shells on $\mathrm{C}, \mathrm{N}, \mathrm{O}$, and $(2+1) p$ shells and $(1+1)$ $d$ shells on $\mathrm{H}$ atoms and hence it provides a more realistic description of higher angular momentum Rydberg-like states than does the $6-31++G(d, p)$ basis set. Nevertheless, population analysis confirmed that all the basis sets used in this work provided a satisfactory qualitative description of excited state orbitals, so any of them could be used for orbital visualization. Geometry optimization of excited states was performed using UCIS calculations [38] with the 6-31 + G(d,p) and 6-311 $++\mathrm{G}(2 \mathrm{~d}, \mathrm{p})$ basis sets.

\section{Results}

\section{Charge Effects on Dissociation of Ammonium Radicals}

The properties of neutral hypervalent ammonium radicals have been thoroughly investigated by previous experimental [39-46] and theoretical studies [40, 41, 47-49]. In their ground doublet states $\left({ }^{2} \boldsymbol{X}\right)$, ammonium radicals such as methylammonium [47, 49], di methylammonium [40], trimethylammonium [41], $\mathrm{NH}_{3} \mathrm{CH}_{2} \mathrm{CH}_{2} \mathrm{CONH}_{2}$ [13], $\mathrm{NH}_{3} \mathrm{CH}_{2} \mathrm{CH}_{2} \mathrm{CONHCH}_{3}$ [13], and $\mathrm{NH}_{3} \mathrm{CH}_{2} \mathrm{CONHCH}_{2} \mathrm{CONHCH}_{3}$ [13] are only weakly bound along the respective $\mathrm{N}-\mathrm{H}$ coordinates, 

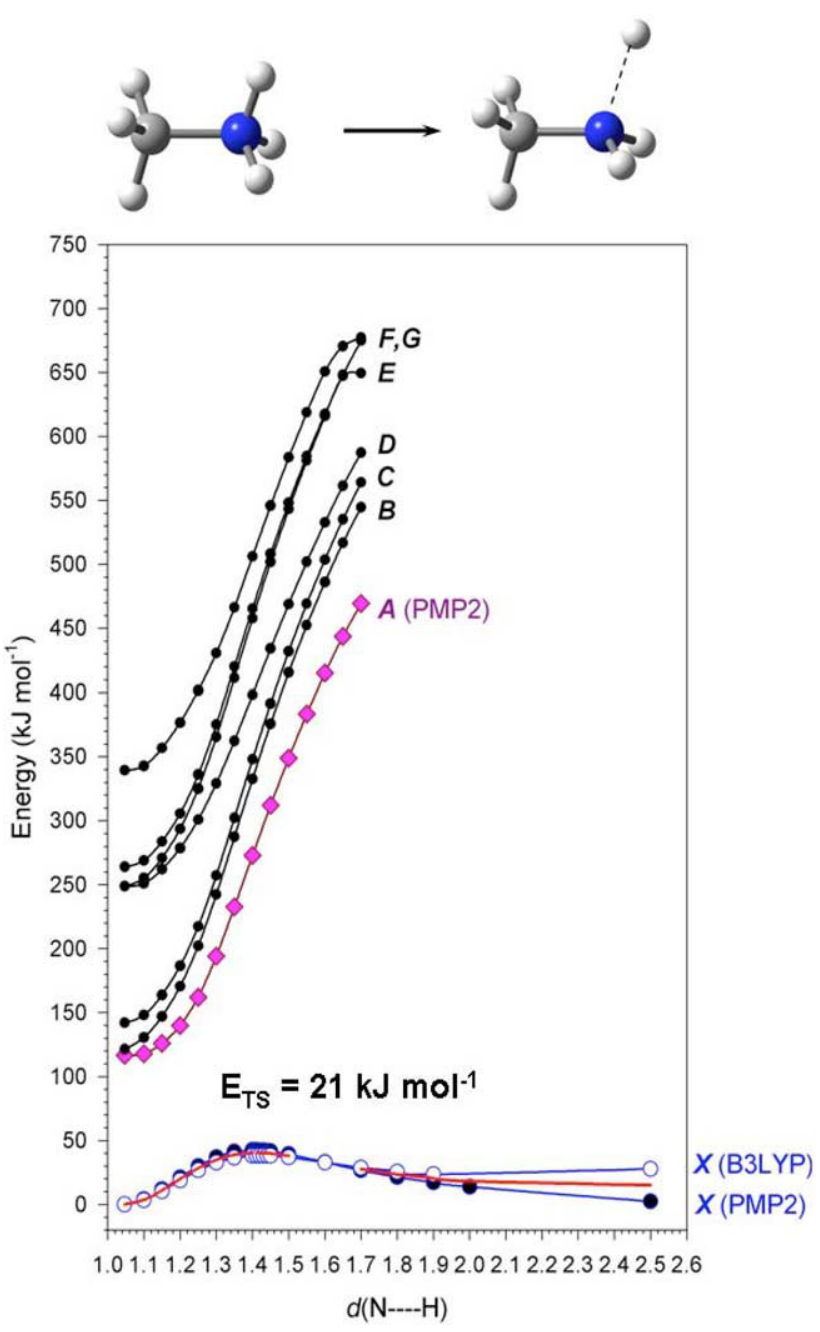

Figure 1. Potential energy surfaces (PES) for $\mathrm{N}-\mathrm{H}$ bond dissociation in the eight lowest electronic states $(X-G)$ of methylammonium radical in the absence of external charge. The PES for the $X$ state were calculated by B3LYP and PMP2/6-311 ++ G(2d,p), as labeled. The PES for the $A$ state was optimized by UCIS/6-311 ++ $\mathrm{G}(2 \mathrm{~d}, \mathrm{p})$ and single-point energies were obtained by PMP2/6-311 $++G(2 d, p)$. The PES for the $\boldsymbol{B}$ and higher excited states are from TD-B3LYP/6-311 + + G(2d,p) vertical excitation energies on optimized $A$ state geometries.

and rapidly dissociate by loss of an ammonium hydrogen atom. In contrast, excited doublet states of neutral ammonium radicals are strongly bound along the $\mathrm{N}-\mathrm{H}$ coordinate $[40,49]$. In the present work we examined the effect of point charges on the $\mathrm{N}-\mathrm{H}$ bond dissociation in methylammonium radical, which is a simple model for ammonium radicals produced by electron capture by the primary $\varepsilon$-ammonium group in protonated lysine residues. The potential energy profile for the $\mathrm{N}-\mathrm{H}$ bond dissociation in the absence of a point charge (Figure 1) shows a low energy barrier in the $X$ state. The energy barrier from B3-PMP2 single-point calculations (21 $\mathrm{kJ} \mathrm{mol}^{-1}$ including ZPVE correction) agrees closely with that from the higher level CCSD(T)/aug-cc-pVTZ calculation $\left(24 \mathrm{~kJ} \mathrm{~mol}^{-1}\right)$, and indicates that the B3PMP2 approximation is adequate for the system under study. In contrast to the $X$ state, the $A$ and higher excited states show continuously increasing potential energies along the $\mathrm{N}-\mathrm{H}$ bond coordinate which indicate that these states are bound.

Placing a positive point charge at various distances along or perpendicular to the $\mathrm{N}-\mathrm{C}$ bond axis results in shifts in the transition state energy for $\mathrm{N}-\mathrm{H}$ bond dissociation in the $X$ state (TS1, Figure 2). A point charge placed perpendicular to the $\mathrm{N}-\mathrm{C}$ bond tends to increase the TS1 energy, thus stabilizing the ammonium radical. A point charge placed along the $\mathrm{N}-\mathrm{C}$ axis closer to the ammonium group also increases the TS1 energy, whereas a charge placed at the opposite end of the radical lowers it. These charge effects are essentially due to electron polarization within the ammonium group. In the absence of a point charge, the electron rich ammonium group carries most of the spin density and shows an unusual bond polarization, in that there is substantial negative charge on the hydrogen atoms which contributes to the destabilization of the $\mathrm{N}-\mathrm{H}$ bonds. The singly occupied molecular orbital (SOMO) in $\mathrm{CH}_{3} \mathrm{NH}_{3}$ is a diffuse Rydberg-like orbital (3s) in which one of the nodal surfaces dissects the $\mathrm{N}-\mathrm{H}$ bonds. A point charge close to the hydrogen atoms causes electron flow away from the $\mathrm{N}-\mathrm{H}$ bond, thus reducing their destabilization. Placing the positive charge close to the electron deficient methyl group raises the energy in $\mathrm{CH}_{3} \mathrm{NH}_{3} \cdot$ more than in TS1, resulting in a decrease of the energy barrier for dissociation.

The effect of point charges on the potential energy surfaces (PESs) of the $A$ and higher excited states is shown in Figure 3 . With the charge along the $\mathrm{C}-\mathrm{N}$ axis close to the $\mathrm{C}$ terminus ( $5 \AA$ ), the energy of the $A$ state drops below that of the $X$ state. However, the potential energy surface for $\mathrm{N}-\mathrm{H}$ bond dissociation in the $A$ state is not changed significantly, in that it shows a continuous energy increase at increasing $\mathrm{N}-\mathrm{H}$ separations. The same holds for the higher excited states (Figure 3). Placing the point charge along the $\mathrm{C}-\mathrm{N}$ axis close to the $\mathrm{N}$ terminus has an even weaker effect in that the PESs of the excited states show substantial continuously increasing energies as the $\mathrm{N}-\mathrm{H}$ bond is stretched. The unequivocal conclusion from these calculations is that the presence of a positive point charge in the vicinity of the hypervalent ammonium radical affects the ground electronic state substantially more than the excited states.

Two additional points are worth mentioning. First, as expected, the charge effects diminish with distance. Second, even at an extremely close distance between the positive charge and the ammonium group $(5 \AA)$, that may, in fact, not be realizable in multiply charged peptide cations because of coulomb repulsion, the $\mathrm{N}-\mathrm{H}$ bond dissociation energies in the $A$ and higher states exceed the recombination energy in the ammonium cation to reach the pertinent electronic state of the radical, making such dissociations energetically impossible. This refutes the speculation that loss of hydrogen in reduced-charge peptides and proteins may occur 

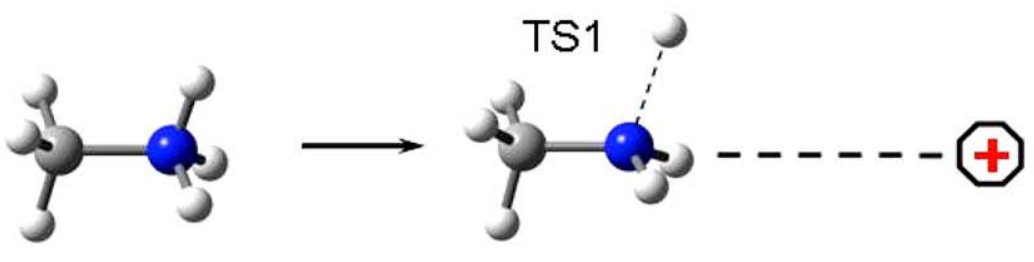

\section{Charge at $5 \mathrm{~A}$ from $\mathrm{N}$}

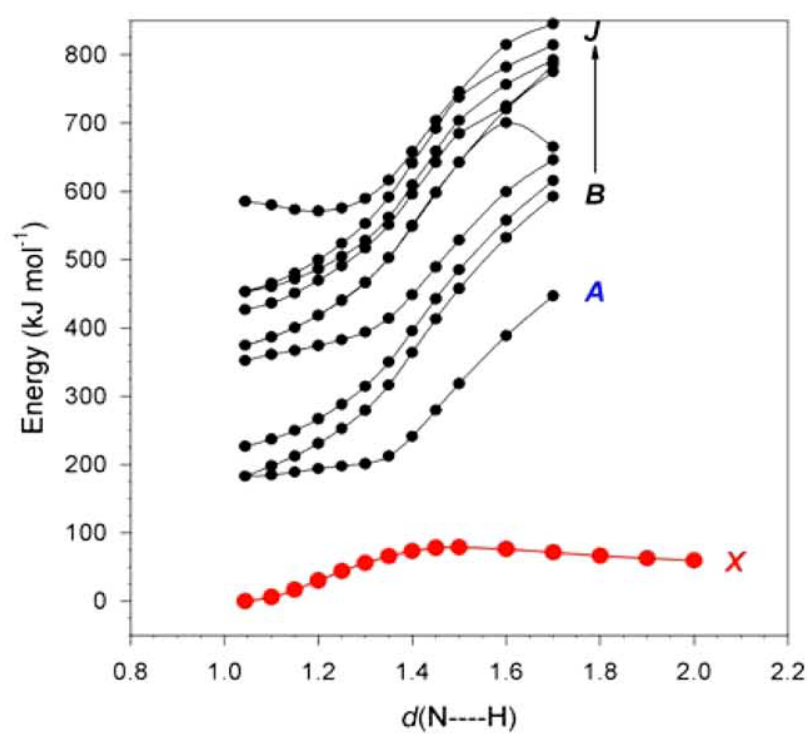

Charge at $10 \mathrm{~A}$ from $\mathrm{N}$

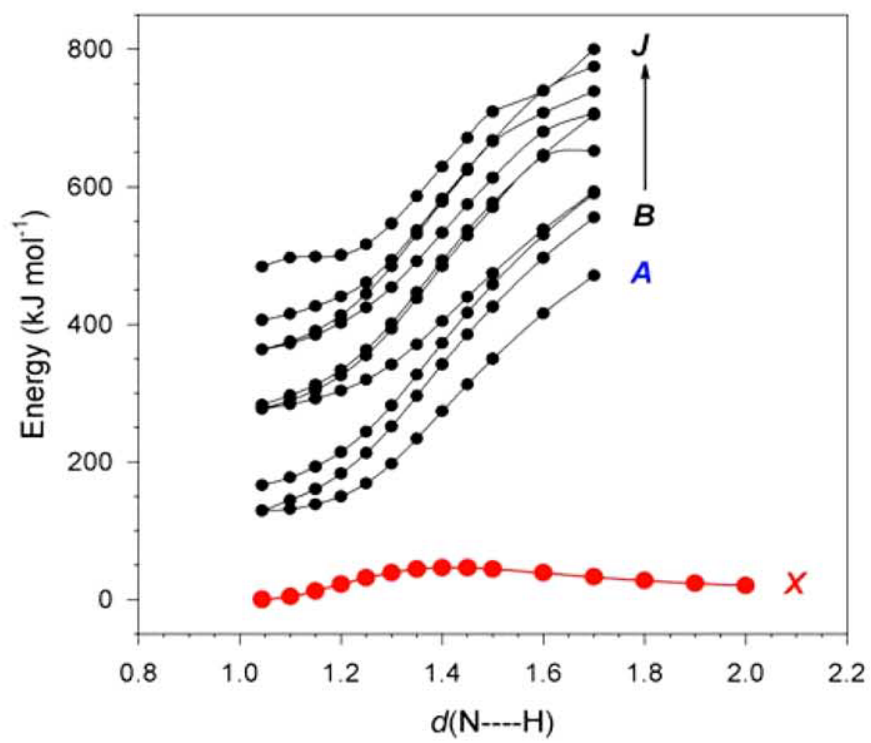

Figure 2. Potential energy surface for $\mathrm{N}-\mathrm{H}$ bond dissociation in the ten lowest electronic states of methylammonium radical in the presence of a point charge in the indicated position.

from an excited electronic state $[8 \mathrm{~b}, 8 \mathrm{c}]$. Note that the $\mathrm{N}-\mathrm{H}$ bond dissociation energy in $\mathrm{CH}_{3} \mathrm{NH}_{3}{ }^{+}(445 \mathrm{~kJ}$ $\mathrm{mol}^{-1}$ ) is comparable to the energy needed to break the same bond in the high excited states of $\mathrm{CH}_{3} \mathrm{NH}_{3}$. The adiabatic recombination energy in $\mathrm{CH}_{3} \mathrm{NH}_{3}{ }^{+}$to reach the $X$ state of $\mathrm{CH}_{3} \mathrm{NH}_{3}$ was calculated by $\mathrm{CCSD}(\mathrm{T}) /$ aug-cc-pVTZ as $4.24 \mathrm{eV}$.

In summarizing this part, the calculations show that excited states of methylammonium radical are strongly bound along the $\mathrm{N}-\mathrm{H}$ coordinate both in the presence and absence of a remote charge. Loss of hydrogen atoms from ammonium radicals, if it occurs, does so from the weakly bound ground electronic state, again regardless of a remote charge.

\section{Charge Effects on Electron Attachment and Dissociations of the Amide Bond}

In the absence of a remote charge, the amide group does not have bound electronic states for capturing an electron in a stable anion-radical, as evidenced by marginal proton affinities of amide-containing molecules [50] and dissociative electron capture in amides [51]. However, in the presence of a positive charge, the coulomb interaction with the incoming electron can result in a stabilization of the anion radical, as shown for dimethyldisulfide [17]. We investigated this stabilization for three model systems involving $\mathrm{N}$-methylacetamide (NMA) in the presence of a point positive charge, a methylammonium cation, and a guanidinium cation.

Point charge models. In order to simulate the background charge distribution experienced by a typical amide group in a multiply-charged peptide ion in the gas phase, point charges were fixed at various orientations relative to the NMA molecule and anion radical. The charges were placed $7 \AA$ from the oxygen atom, corresponding to the distance between neighboring carbonyl groups on the same side of the peptide backbone in a $\beta$-sheet conformation [52], and at varying angles to $\mathrm{C}=\mathrm{O}$ and varying dihedral angles to $\mathrm{N}-\mathrm{C}=\mathrm{O}$. Of the orientations investigated, the most favorable charge position was found at $120^{\circ}$ to $\mathrm{C}=\mathrm{O}$, and in the plane of the anion radical on the $\mathrm{N}$-methyl side $\left(\mathrm{N}-\mathrm{C}=\mathrm{O}-\oplus\right.$ dihedral angle $\left.=0^{\circ}\right)(1 \mathrm{a}$, Figure 4). The other point charge positions were at $120^{\circ}$ to $\mathrm{C}=\mathrm{O}$, $7 \AA$ from the oxygen atom, and out of the plane of the anion radical $\left(\mathrm{N}-\mathrm{C}=\mathrm{O}-\oplus\right.$ dihedral angle $\left.=90^{\circ}\right)(\mathbf{1 b})$, at $120^{\circ}$ to $\mathrm{C}=\mathrm{O}, 7 \AA$ from the oxygen atom, and in the plane of the anion radical on the $\mathrm{C}$-methyl side $\left(\mathrm{N}-\mathrm{C}=\mathrm{O}-\oplus\right.$ dihedral angle $\left.=180^{\circ}\right)(\mathbf{1 c})$, and as in 1a but at $10 \AA$ from the oxygen atom (1d) (Table 1).

1a was calculated to have a positive electron affinity of 2.5-3.4 eV, depending on the basis set used (Table 1). 

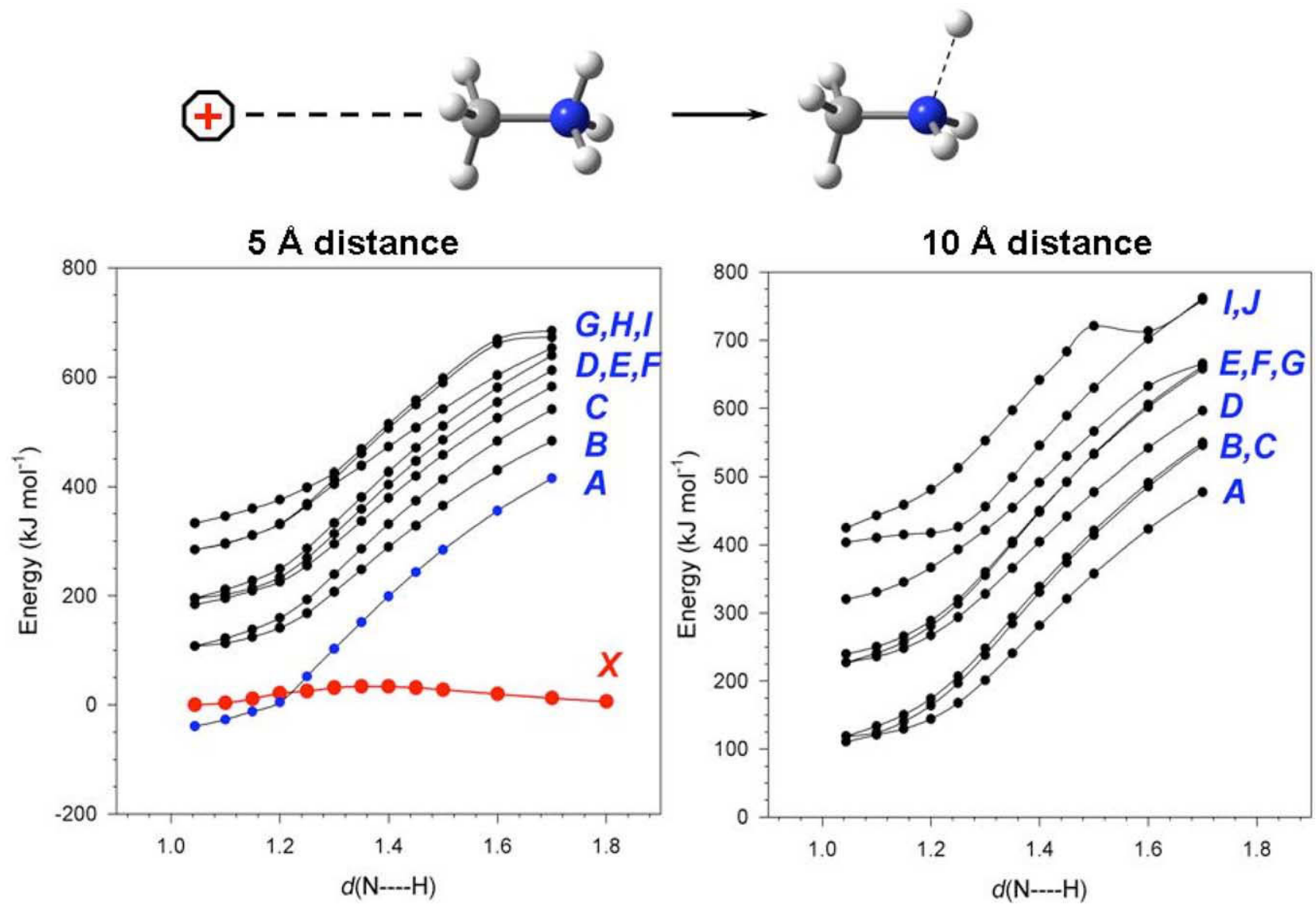

Figure 3. Potential energy surface for $\mathrm{N}-\mathrm{H}$ bond dissociation in the ten lowest electronic states of methylammonium radical in the presence of a point charge in the indicated position.

Hence, the incoming electron experiences a substantial binding energy in $1 a^{-*}$. The electron affinity of $1 \mathrm{a}$ is reduced to $1.11-1.41 \mathrm{eV}$ by extending the charge-to-
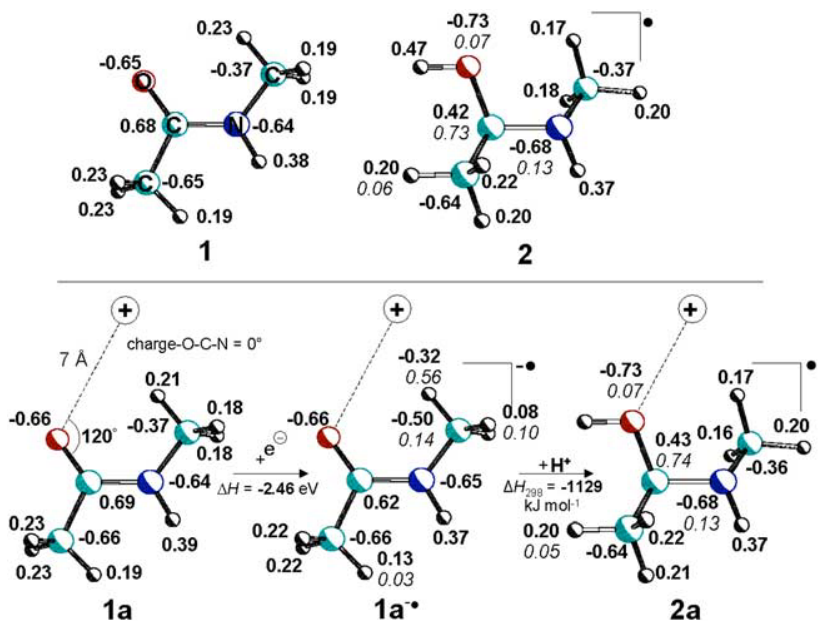

Figure 4. NPA charge and spin densities for $1, \mathbf{1}^{--}$, and $\mathbf{2}$ in the absence of a point charge (top), and for $1 \mathbf{a}, 1 \mathbf{a}^{-\cdot}$, and $2 \mathbf{a}$ with the most stabilizing point charge geometry (bottom). Charge densities are in bold, and spin densities are in italics. Reaction enthalpies are based on vertically-produced $\mathbf{1}^{-\cdot}$ and $1 \mathbf{a}^{-\cdot}$, and do not include ZPVE corrections. oxygen distance to $10 \AA$ (1d). Table 1 displays the results of other point charge orientations, all of which stabilize the anion radical significantly, leading to universally positive electron affinities for NMA.

The charge and spin densities in $\mathbf{1 a}^{-\cdot}$ are accumulated at the N-methyl group, particularly at the in-plane hydrogen (Figure 4). The ground state singly-occupied molecular orbital (SOMO) of the anion radical shows the unpaired electron in a Rydberg orbital, which is oriented near the N-methyl group, about halfway between oxygen and the stabilizing positive charge (Figure 5). The $X$ state of $1 a^{-\cdot}$ was calculated to have a proton affinity (PA) of 1027-1121 $\mathrm{kJ} \mathrm{mol}^{-1}$, depending on the basis set used. The PA for the $X$ state of $\mathbf{1 b}^{-\cdot}$ was calculated as $1229 \mathrm{~kJ} \mathrm{~mol}^{-1}$. Proton affinity differences are dominated by differences in the relative reactant energies, as unlike in anion radicals $1 \mathbf{a}^{-\cdot}$ and $1 \mathbf{b}^{-}$, point charge stabilization of the respective protonation products ( $\mathbf{2 a}$ and $\mathbf{2 b}$ ) is minor, and nearly identical in the in-plane (2a) and out-of-plane (2b) point charge systems (15 and $14 \mathrm{~kJ} \mathrm{~mol}^{-1}$, respectively). Assuming that a peptide backbone amide group has similar energetics as the NMA model systems, proton transfer from any protonated site to the amide anion radical ground state would be energetically favorable, as even the most basic 
Table 1. N-methylacetamide electron affinities

Point charge geometry

\begin{tabular}{lrcrc} 
Product & $d(\mathrm{O}-\oplus)^{\mathrm{a}}$ & $A(\mathrm{C}=\mathrm{O}-\oplus)^{\mathrm{b}}$ & $D(\mathrm{~N}-\mathrm{C}=\mathrm{O}-\oplus)^{\mathrm{c}}$ & $\mathrm{EA}_{v}{ }^{\mathrm{d}}$ \\
\hline \hline$(X) \mathbf{1} \mathbf{a}^{-\cdot}$ & $7 \AA$ & $120^{\circ}$ & $0^{\circ}$ & $2.46(2.52)^{\mathrm{e}}(3.45)^{\mathrm{f}}$ \\
$(E) \mathbf{1} \mathbf{a}^{-\cdot}$ & $7 \AA$ & $120^{\circ}$ & $0^{\circ}$ & $0.57(0.63)^{\mathrm{e}}(0.98)^{\mathrm{f}}$ \\
$(X) \mathbf{1} \mathbf{b}^{-\cdot}$ & $7 \AA$ & $120^{\circ}$ & $90^{\circ}$ & 1.31 \\
$(D) \mathbf{1} \mathbf{b}^{-\cdot}$ & $7 \AA$ & $90^{\circ}$ & 0.17 \\
$(X) \mathbf{1} \mathbf{c}^{-.}$ & $7 \AA$ & $120^{\circ}$ & $180^{\circ}$ & 1.41 \\
$(X) \mathbf{1} \mathbf{d}^{-\cdot}$ & $10 \AA$ & $120^{\circ}$ & $0^{\circ}$ & $1.11(1.13)^{\mathrm{e}}(1.41)^{\mathrm{f}}$ \\
\hline
\end{tabular}

aDistance between the point charge and the $\mathrm{N}$-methylacetamide oxygen.

${ }^{b}$ Angle between the point charge and the $\mathrm{N}$-methylacetamide carbonyl bond.

'Dihedral angle between the point charge and $\mathrm{O}=\mathrm{C}-\mathrm{N}$ in $\mathrm{N}$-methylacetamide.

dEnergy difference in units of electronvolts between the optimized molecule and vertically neutralized anion radical structures from B3LYP/6- 311 ++ $\mathrm{G}(2 \mathrm{~d}, \mathrm{p})$ calculations.

eB3LYP/6-311 ++ G(3df,2pd) energies.

${ }^{\mathrm{f} B} 3 \mathrm{~L}$ YP/aug-cc-pVTZ energies.

side group, arginine, has a significantly lower PA of $1051 \mathrm{~kJ} \mathrm{~mol}^{-1}[53,54]$.

Also shown in Figure 5 are molecular orbitals for the first five excited electronic states of $1 \mathbf{a}^{-\cdot}$, as well as their corresponding vertical excitation energies and radiative lifetimes. These were determined by TD-B3LYP with the 6-311 ++ G(2d,p), 6-311 ++ G(3df,2pd), and augcc-pVTZ basis sets. Increasing the basis set from 6-31 $++\mathrm{G}(\mathrm{d}, \mathrm{p})$ (216 gaussians) to aug-cc-pVTZ (554 gaussians) resulted in a substantial decrease in the $\boldsymbol{X}$ state energy in $1 \mathrm{a}^{-}$, which increased the electron affinity and the excitation energies for the $A-I$ excited states. Molec-

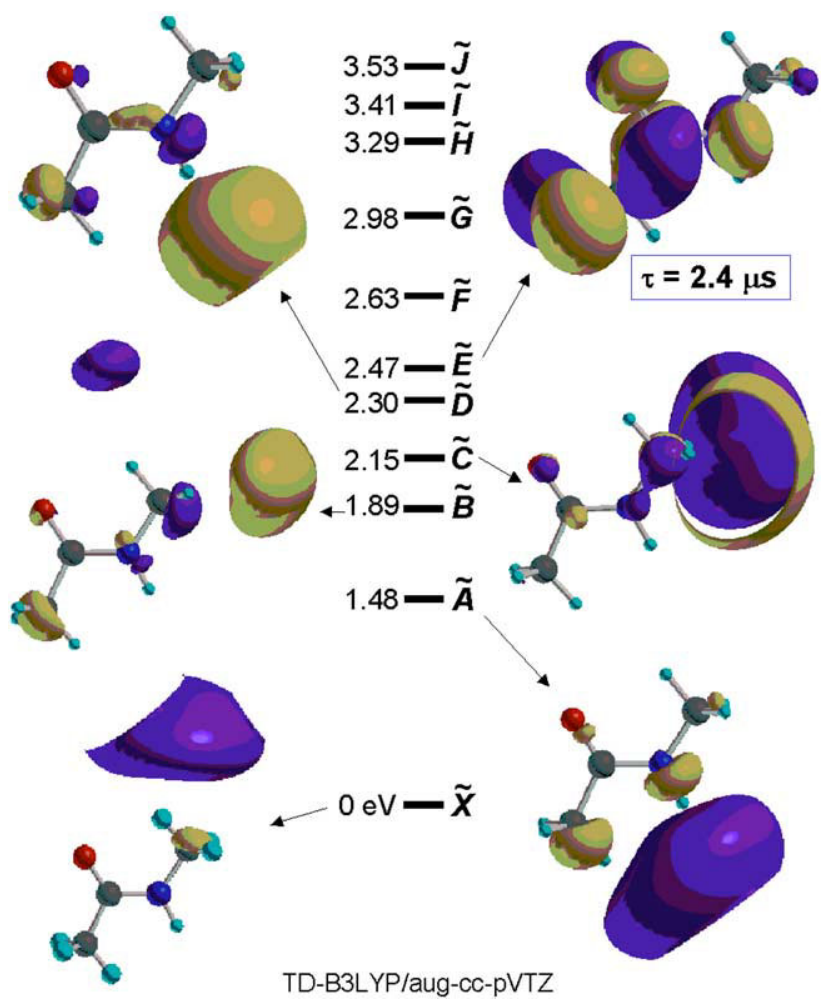

Figure 5. TD-B3LYP/aug-cc-pVTZ molecular orbitals for the $X$ through $E$ states of $1 \mathrm{a}^{-\cdot}$. Vertical excitation energies are in units of electron volts. ular orbitals were calculated by scaling and mixing the virtual orbitals of ground state $1 \mathbf{a}^{-\cdot}$ according to excitation configurations and expansion coefficients calculated from time-dependent DFT calculations with the 6-311 + + G(2d,p) basis set. In the context of ECD, to be of relevance in the formation of an aminoketyl radical by protonation, a given electronic state of an amide anion radical must fulfill three requirements: (1) the amide group should have substantial electron density, favoring protonation of the carbonyl oxygen; (2) the excited state should have a relatively long lifetime on a time scale such that intramolecular proton transfer of $k$ $\approx 10^{12} \mathrm{~s}^{-1}$ (reference [13]) be faster than the rate of decay to a lower state; and (3) the excitation energy must be below the ionization limit of the anion radical, such that vertical electron attachment to the precursor amide group is exothermic. As seen in Figure 5, these conditions are satisfied by the $E$ state of $\mathbf{1 a}^{-\cdot}$ (vertical excitation energy, $\Delta E_{\text {exc }}=2.47 \mathrm{eV}$ ), in which the electron density is delocalized over the amide and $\mathrm{N}$ methyl groups in an antibonding- $\pi$ type orbital, and electron attachment to $\mathbf{1 a}$ to form this state is exothermic by $0.98 \mathrm{eV}$. The radiative lifetime of $(E) \mathbf{1 a}^{-\cdot}$ was calculated as $\tau=2.4 \mu \mathrm{s}$ from the relationship below (eq 1 ), where $\varepsilon_{0}$ is the permittivity of a vacuum, $m_{e}$ is the electron rest mass, $c$ is the speed of light, $e$ is the fundamental charge, $f$ is the oscillator strength, and $v$ is the transition wavenumber.

$$
\tau=\frac{\varepsilon_{0} m_{e} c}{2 \pi f e^{2} v^{2}}
$$

Although we did not calculate non-radiative lifetimes of the excited states of interest, a recent study indicates that metastable excited states in charge-reduced radicals can have lifetimes on the order of microseconds [55]. The PA of $(E) 1 \mathbf{a}^{-\cdot}$ was calculated as $1265-1311 \mathrm{~kJ}$ $\mathrm{mol}^{-1}$ from the $X$ state PA and $\Delta E_{\text {exc }}$ for $X \rightarrow E$ excitation (Table 2). Similar excited state calculations were performed on the out-of-plane point charge system $\mathbf{1 b}^{-}$, and orbital analysis indicated significant 
Table 2. N-methylacetamide anion radical proton affinities Point charge geometry

\begin{tabular}{lccccc} 
Reactant & Product & $d(\mathrm{O}-\oplus)^{\mathrm{a}}$ & $A(\mathrm{C}=\mathrm{O}-\oplus)^{\mathrm{b}}$ & $D(\mathrm{~N}-\mathrm{C}=\mathrm{O}-\oplus)^{\mathrm{c}}$ & $\mathrm{PA}^{\mathrm{d}}$ \\
\hline \hline$(X) \mathbf{1} \mathbf{a}^{-\cdot}$ & $\mathbf{2 a}$ & $7 \AA$ & $120^{\circ}$ & $0^{\circ}$ & $1121(1115)^{\mathrm{e}}(1027)^{\mathrm{f}}$ \\
$(E) \mathbf{1} \mathbf{a}^{-\cdot}$ & $\mathbf{2 a}$ & $7 \AA$ & $120^{\circ}$ & $0^{\circ}$ & $1311(1298)^{\mathrm{e}}(1265)^{\mathrm{f}}$ \\
$(X) \mathbf{1} \mathbf{b}^{-}$ & $\mathbf{2 b}$ & $7 \AA$ & $120^{\circ}$ & $90^{\circ}$ & 1229 \\
$(D) \mathbf{1} \mathbf{b}^{-\cdot}$ & $\mathbf{2 b}$ & $7 \AA$ & $120^{\circ}$ & $90^{\circ}$ & 1354 \\
\hline
\end{tabular}

${ }^{a}$ Distance between the point charge and the $\mathrm{N}$-methylacetamide oxygen.

${ }^{b}$ Angle between the point charge and the $\mathrm{N}$-methylacetamide carbonyl bond.

'Dihedral angle between the point charge and $\mathrm{O}=\mathrm{C}-\mathrm{N}$ in $\mathrm{N}$-methylacetamide.

${ }^{\mathrm{d} N e g a t i v e ~ r e a c t i o n ~ e n t h a l p y ~ i n ~ u n i t s ~ o f ~ k i l o j o u l e s ~ p e r ~ m o l e ~ a t ~} 298 \mathrm{~K}$ at B3LYP/6-311 ++ G(2d,p).

eB3LYP/6-311 ++ G(3df,2pd) energies.

${ }^{f} B 3 L Y P / a u g-c c-p V T Z$ energies.

amide electron density in the $D$ state $\left(\Delta E_{\text {exc }}=1.14 \mathrm{eV}\right.$, $\tau=3.1 \mu \mathrm{s})$. The PA of $(\boldsymbol{D}) \mathbf{1} \mathbf{b}^{-\cdot}$ was calculated as $1354 \mathrm{~kJ}$ $\mathrm{mol}^{-1}$. Proton affinities for the relevant electronic states of $1 \mathbf{a}^{-\cdot}$ and $\mathbf{1 b}^{-\cdot}$ are summarized in Table 2 .

In order to address the possibility of a previously suggested "direct dissociative electron attachment" mechanism $[8 b, 8 c]$, it was desirable to determine the relative reactivity of charge-stabilized NMA anion radicals as compared to Radical 2, the product of anion radical protonation. Reaction enthalpies for $\mathrm{N}-\mathrm{CH}_{3}$ cleavage were determined for $1 \mathbf{a}^{-\cdot}$ (the most stabilizing point charge) and $\mathbf{1} \mathbf{c}^{-\cdot}$ (point charge on the C-methyl side of the carbonyl group; $\mathrm{N}-\mathrm{C}=\mathrm{O}-\oplus$ dihedral angle $=180^{\circ}$ ). For each set of reaction products, single-point energies were determined for the acetimido anion $\left(\mathrm{CH}_{3} \mathrm{CO}=\mathrm{NH}^{-}\right)$in the presence of the appropriate charge, and for isolated methyl radical. UB3LYP/6-311 $++\mathrm{G}(2 \mathrm{~d}, \mathrm{p})$ frequency analysis of reactants and products in the absence of a point charge yielded ZPVEs which were used to determine $0 \mathrm{~K}$ reaction enthalpies, summarized in Table 3 . The $\mathrm{N}-\mathrm{C}_{\alpha}$ bond dissociation energies in both the $\mathrm{C}$-methyl point charge model $1 \mathrm{c}^{- \text {. }}$ (86 kJ mol ${ }^{-1}$, respectively), and N-methyl point charge model $\mathbf{1 a}^{-\cdot}\left(165 \mathrm{~kJ} \mathrm{~mol}^{-1}\right)$ are substantially greater than in Radical 2. This indicates a greater charge stabilization of the anion radical reactants relative to the dissociation products.

To determine transition state energies, the PES for
$\mathrm{N}-\mathrm{C}$ dissociation was calculated by stretching this coordinate at 0.03 to $0.10 \AA$ increments, while allowing all other internal degrees of freedom to fully optimize by UB3LYP/6-31 + G(d,p). A stationary point was found at $r(\mathrm{~N}-\mathrm{C})=1.895 \AA$, and was characterized as a first-order saddle point by having one imaginary frequency ( $\mathrm{N}-\mathrm{C}$ stretching mode). The PES for $\mathrm{N}-\mathrm{C}$ cleavage in $\mathbf{1 a}^{-\cdot}$ and $\mathbf{1 \mathbf { c } ^ { - \cdot }}$ was then mapped according to a method described previously $[10,11]$, in which higher-level single-point energy calculations were performed on several structures near the saddle point. The energy barriers for $\mathrm{N}-\mathrm{C}_{\alpha}$ cleavage in $1 \mathbf{a}^{-\cdot}$ and $1 \mathrm{c}^{-\cdot}$ were as 200 and $143 \mathrm{~kJ} \mathrm{~mol}^{-1}$, respectively. These follow the same general trend as the corresponding reaction enthalpies. G2(MP2) calculations for $1 \mathbf{c}^{-\cdot}$ gave both a lower reaction enthalpy of $62 \mathrm{~kJ} \mathrm{~mol}^{-1}$ and a lower transition state energy of $102 \mathrm{~kJ} \mathrm{~mol}^{-1}$. The corresponding G2(MP2) reaction enthalpy and energy barrier for $\mathrm{N}-\mathrm{C}_{\alpha}$ dissociation in isolated Radical 2 were calculated previously as 10 and $84 \mathrm{~kJ} \mathrm{~mol}^{-1}$, respectively [11]. These values would be expected to change very little in the presence of point charges, based on the minor charge stabilization energies of Reactant $\mathbf{2}$ as discussed above. The calculated energies point to the possibility of direct ground state dissociation of NMA anion radical in certain favorable point charge orientations, with a general increase in the radical reactivity following protonation to form the neutral ketyl Radical 2. Interest-

Table 3. Dissociation energetics of $1 \mathrm{a}^{-*}, 1 \mathrm{c}^{-*}$, and 2

\begin{tabular}{|c|c|c|c|c|c|}
\hline \multirow[b]{2}{*}{ Reaction/species } & \multicolumn{5}{|c|}{ Point charge geometry } \\
\hline & $d(0-\oplus)^{a}$ & $A(\mathrm{C}=\mathrm{O}-\oplus)^{\mathrm{b}}$ & $D(\mathrm{~N}-\mathrm{C}=\mathrm{O}-\oplus)^{\mathrm{c}}$ & B3LYPd & $\mathrm{G} 2(\mathrm{MP} 2)^{\mathrm{e}}$ \\
\hline $1 \mathbf{a}^{-\cdot} \rightarrow \mathrm{CH}_{3} \mathrm{CONH}^{-}+\mathrm{CH}_{3}{ }^{-}$ & $7 \AA$ & $120^{\circ}$ & $0^{\circ}$ & 165 & - \\
\hline $1 \mathbf{c}^{-\cdot} \rightarrow \mathrm{CH}_{3} \mathrm{CONH}^{-}+\mathrm{CH}_{3}^{\cdot}$ & $7 \AA$ & $120^{\circ}$ & $180^{\circ}$ & 86 & 62 \\
\hline TS $\left(1 \mathrm{a}^{-\cdot} \rightarrow \mathrm{CH}_{3} \mathrm{CONH}^{-}+\mathrm{CH}_{3}{ }^{-}\right)$ & $7 \AA$ & $120^{\circ}$ & $0^{\circ}$ & 200 & - \\
\hline TS $\left(1 \mathrm{c}^{--} \rightarrow \mathrm{CH}_{3} \mathrm{CONH}^{-}+\mathrm{CH}_{3}^{-}\right)$ & $7 \AA$ & $120^{\circ}$ & $180^{\circ}$ & 143 & 102 \\
\hline $2 \rightarrow \mathrm{CH}_{3} \mathrm{C}(\mathrm{OH})=\mathrm{NH}+\mathrm{CH}_{3}$ & & no charge & - & - & $10^{f}$ \\
\hline TS $\left(2 \rightarrow \mathrm{CH}_{3} \mathrm{C}(\mathrm{OH})=\mathrm{NH}+\mathrm{CH}_{3}{ }^{-}\right)$ & & no charge & - & - & $84^{f}$ \\
\hline
\end{tabular}

aDistance between the point charge and the $\mathrm{N}$-methylacetamide oxygen.

${ }^{b}$ Angle between the point charge and the $\mathrm{N}$-methylacetamide carbonyl bond.

'Dihedral angle between the point charge and $\mathrm{O}=\mathrm{C}-\mathrm{N}$ in $\mathrm{N}$-methylacetamide.

${ }^{d} 0 \mathrm{~K}$ energies in units of kilojoules per mole at B3LYP/6-311 $\left.++\mathrm{G}(2 \mathrm{~d}, \mathrm{p})\right)$.

${ }^{\mathrm{e}} \mathrm{O} \mathrm{K}$ energies in units of kilojoules per mole at G2(MP2).

${ }^{\mathrm{f}}$ From reference [11]. 


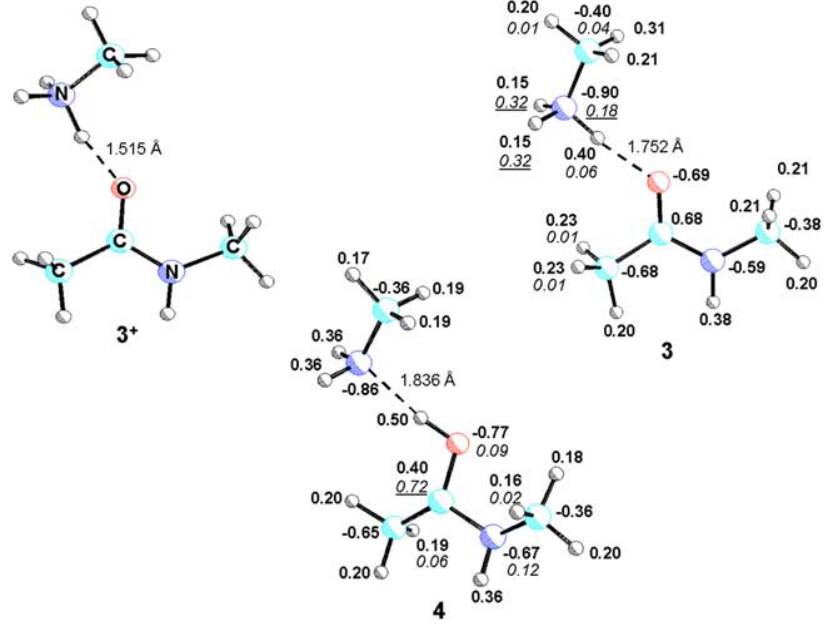

Figure 6. NPA charge and spin densities for Structures $3^{+}, 3$, and 4. Charge densities are in bold, and spin densities are in italics.

ingly, as the charge stabilization which promotes electron attachment to NMA increases, direct, facile dissociation in the $X$ state of the resulting anion radical is significantly inhibited.

Methylammonium charge models: Optimized structures. To provide a chemically more accurate representation of a neighboring charged group in a peptide ion, the point charge was replaced with a methylammonium cation, simulating the protonated $\varepsilon$-ammonium group of a lysine. Several methylammonium orientations were investigated. In the first system, representing the closest approach of the NMA and $\mathrm{CH}_{3} \mathrm{NH}_{3}{ }^{+}$moieties, a proton-bound complex $\left(3^{+}\right)$was fully optimized and then discharged by adding an electron to give a radical which was reoptimized (3). Proton migration from the ammonium group onto the amide carbonyl oxygen gave hydrogen bonded complex of Radical 2 with methylamine (Structure 4). Structures $3^{+}, 3$, and 4 show features (Figure 6) that are analogous to $\mathrm{N}_{\alpha}$-acetyl lysine amide cations and radicals reported previously [13]. In particular, the ammonium group in $3^{+}$forms a strong hydrogen bond to the amide carbonyl at a $1.515 \AA$ H. . .O distance (Figure 6). The hydrogen bond is weaker in Radical 3 (1.752 $\AA$ ). Hydrogen transfer to the oxygen atom is $39 \mathrm{~kJ} \mathrm{~mol}^{-1}$ exothermic to form 4, in which the $\mathrm{OH}$ proton is hydrogen bonded to the amino group at a $1.836 \AA$ distance (Figure 6).

In the second system, the methylammonium nitrogen was fixed $7 \AA$ from the NMA oxygen, and the $\mathrm{O}-\mathrm{NH}_{3}-\mathrm{CH}_{3}$ angle was frozen at $180^{\circ}$ but at different conformations. In the first conformation $\left(3 \mathbf{a}^{+}\right)$, separately optimized methylammonium cation and NMA were oriented such that the $\mathrm{C}=\mathrm{O}-\mathrm{N}$ angle was $120^{\circ}$, and the methylammonium was in the plane of NMA $\left(\mathrm{N}-\mathrm{C}=\mathrm{O}-\mathrm{N}\right.$ dihedral angle $=0^{\circ}$ ) (Figure 7). This corresponds to the most stabilizing point charge orientation 1a, as discussed above. A second conformation $\left(3 b^{+}\right)$was studied in which the $\mathrm{O}-\mathrm{N}$ and $\mathrm{O}-\mathrm{N}-\mathrm{C}$ coordinates were frozen at $7 \AA$ and $180^{\circ}$, respectively, while allowing all remaining degrees of freedom to optimize. The methylammonium ion in $3 \mathbf{b}^{+}$is very nearly in the plane of NMA, slightly on the C-methyl side $\left(\mathrm{C}=\mathrm{O}-\mathrm{N}=167^{\circ}, \mathrm{N}-\mathrm{C}=\mathrm{O}-\mathrm{N}=178^{\circ}\right)$. Intramolecular geometry differences between the independently optimized NMA and methylammonium in $3 \mathrm{a}^{+}$ and the same structures in $3 \mathbf{b}^{+}$are negligible, and a modest stabilization energy of $11 \mathrm{~kJ} \mathrm{~mol}^{-1}$ was calculated for the $3 \mathrm{a}^{+} \rightarrow 3 \mathrm{~b}^{+}$relaxation. Additionally, $3 \mathrm{a}^{+}$ was calculated to be only $8 \mathrm{~kJ} \mathrm{~mol}^{-1}$ lower in energy than infinitely separated $\mathbf{1}$ and $\mathrm{CH}_{3} \mathrm{NH}_{3}{ }^{+}$, indicating negligible bonding interaction between the two moieties at $7 \AA$ separation.

In the third system $\left(3 c^{+}\right)$, separately optimized methylammonium cation and NMA were placed at $15 \AA$ separation and oriented such that the $\mathrm{C}=\mathrm{O}-\mathrm{N}$ angle was $120^{\circ}$, and the methylammonium was in the plane of NMA $\left(\mathrm{N}-\mathrm{C}=\mathrm{O}-\mathrm{N}\right.$ dihedral angle $\left.=0^{\circ}\right)$.

Methylammonium charge models: Energetics and electronic states. In this section we compare the recombination energies of [NMA. . $\left.\mathrm{CH}_{3} \mathrm{NH}_{3}\right]^{+}$complexes and excitation energies in the [NMA. . $\mathrm{CH}_{3} \mathrm{NH}_{3}$ ] radicals. Vertical

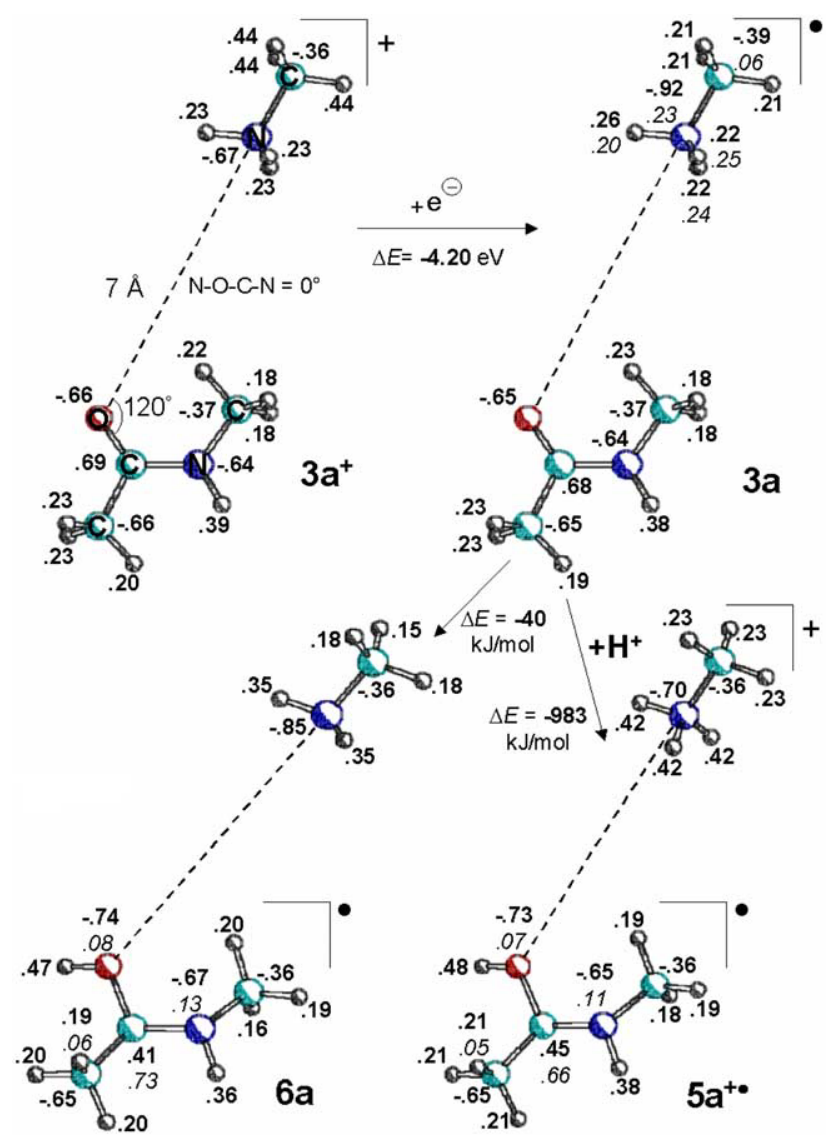

Figure 7. NPA charge and spin densities for $3 \mathrm{a}^{+}, \mathbf{3 a}, \mathbf{4 \mathbf { a } ^ { + }}$, and $\mathbf{5 a}$. Charge densities are in bold, and spin densities are in italics. Reaction enthalpies are based on vertically-produced $\mathbf{3} \mathbf{a}$, and do not include ZPVE corrections. 
Table 4. Electron affinities of $3 a^{+}-3 b^{+}$and $7 a^{+}-7 d^{+}$

\begin{tabular}{|c|c|c|c|c|c|}
\hline Reactant & Product state & $\mathrm{EA}_{v}{ }^{\mathrm{a}}$ & Reactant & Product state & $\mathrm{EA}_{v}{ }^{\mathrm{a}}$ \\
\hline $3^{+}$ & $x$ & $3.13(3.13)^{b}(3.15)^{c}$ & $7 a^{+}$ & $x$ & 3.56 \\
\hline $3 \mathbf{a}^{+}$ & $x$ & $4.20(4.20)^{b}(4.20)^{c}$ & $7 a^{+}$ & $I$ & 1.24 \\
\hline $3 a^{+}$ & $I$ & $1.50(1.50)^{\mathrm{b}}(1.55)^{\mathrm{c}}$ & $7 a^{+}$ & $\boldsymbol{P}$ & 0.25 \\
\hline $3 a^{+}$ & 0 & $0.49(0.51)^{\mathrm{b}}(0.84)^{\mathrm{c}}$ & $7 b^{+}$ & $x$ & 3.47 \\
\hline $3 \mathbf{b}^{+}$ & $x$ & 4.07 & $7 b^{+}$ & $I$ & 1.32 \\
\hline \multirow[t]{7}{*}{$3 b^{+}$} & 0 & 0.53 & $7 b^{+}$ & $P$ & 0.27 \\
\hline & & & $7 c^{+}$ & $x$ & 3.53 \\
\hline & & & $7 c^{+}$ & $I$ & 1.31 \\
\hline & & & $7 c^{+}$ & 0 & 0.31 \\
\hline & & & $7 d^{+}$ & $x$ & 3.39 \\
\hline & & & $7 d^{+}$ & $\boldsymbol{H}$ & 1.41 \\
\hline & & & $7 d^{+}$ & $P$ & 0.29 \\
\hline
\end{tabular}

${ }^{a}$ Energy difference in units of electronvolts between the $\mathrm{N}$-methylacetamide molecule---cation and the vertically neutralized radical structures at B3LYP/6-311 + + G(2d,p).

${ }^{\mathrm{b}} \mathrm{B} 3 \mathrm{LYP} / 6-311++\mathrm{G}(3 \mathrm{df}, 2 \mathrm{pd})$ energies.

'B3LYP/aug-cc-pVTZ energies.

electron recombination energies in $3^{+}, 3 \mathbf{a}^{+}, 3 \mathbf{b}^{+}$, and $3 \mathrm{c}^{+}$were calculated as $3.15,4.20,4.07$, and $4.26 \mathrm{eV}$, respectively (Table 4$)$. The adiabatic values were similar, e.g., 3.36, 4.19, 4.06, and $4.26 \mathrm{eV}$, respectively. Use of the computationally more affordable vertical energies for calculating reaction enthalpies in this and subsequent systems was therefore deemed reasonable. The values for $3 \mathrm{a}^{+}, 3 \mathbf{b}^{+}$, and $3 \mathrm{c}^{+}$are very close to the vertical recombination energy of $\mathrm{CH}_{3} \mathrm{NH}_{3}{ }^{+}(4.28 \mathrm{eV})$, indicating that electron attachment to these cations in the ground state involves the $\mathrm{CH}_{3} \mathrm{NH}_{3}{ }^{+}$moiety rather than the NMA amide group. The electronic states involved in electron capture are represented by vertically reduced $3^{+}$(closest NMA. . $\mathrm{CH}_{3} \mathrm{NH}_{3}$ approach, Figure 8), and $3 \mathbf{a}^{+}$(Figure 9). In both cases, the lowest singly-occupied molecular orbital (SOMO) is a diffuse $s$-type, symmetry-adjusted Rydberg orbital located at the ammonium group. The excited states consist of two manifolds. The first, densely packed manifold contains Rydberg-like diffuse $s, p$, and $d$ orbitals in the $\boldsymbol{B}$ through $\boldsymbol{F}$ and higher states in $\mathbf{3}$ and the $\boldsymbol{A}$ through $\boldsymbol{H}$ states in $\mathbf{3 a}$. The second manifold involves the amide $\pi^{*}$ orbitals that represent the $A$ state in $\mathbf{3}$ of excitation energy $\Delta E_{\text {exc }}=$ $0.54 \mathrm{eV}$ and the $I$ and $O$ states in $3 \mathrm{a}\left(\Delta E_{\text {exc }}=2.65\right.$ and $3.36 \mathrm{eV}$, respectively) and also in $3 \mathrm{c}(2.81$ and $3.45 \mathrm{eV}$, respectively). The relative positions of the first ten excited states for $\mathbf{3}, \mathbf{3} \mathbf{a}$ and $\mathbf{3} \mathbf{c}$ are summarized in Figure 10. Noteworthy is the position of the lowest $\pi^{*}$ state which is very sensitive to the $\mathrm{O}$...N distance.

An important property of the electronic states in 3, 3a and $3 c$ is their proton affinity. This was studied for O-protonation in Radical 3a which was calculated to be overall $983 \mathrm{~kJ} \mathrm{~mol}^{-1}$ exothermic. Note, however, that the ground electronic state of the product $\left(5 \mathbf{a}^{+\cdot}\right.$, Figure $7)$ is the [1-hydroxy-1-( $N$-methyl)aminomethyl radical. . $\mathrm{CH}_{3} \mathrm{NH}_{3}{ }^{+}$] complex which has most of the positive charge in the $\mathrm{CH}_{3} \mathrm{NH}_{3}$ moiety and thus does not gauge the topical proton affinity of the amide carbonyl in 3a. To estimate the latter, one has to consider excited electronic states in $\mathbf{5} \mathbf{a}^{+}$, in which the electron distribution corresponds to [1-hydroxy-1-( $N$ methyl)aminomethyl cation. . $\mathrm{CH}_{3} \mathrm{NH}_{3}{ }^{\circ}$, the electron occupies one of the $3 s$ ( $\boldsymbol{A}$ state) and $3 p$ (B-D states) Rydberg orbitals at $\mathrm{CH}_{3} \mathrm{NH}_{3}$, and the positive charge has moved to the NMA moiety. The topical proton affinity of NMA in 3a was estimated from a thermochemical cycle as follows. First, the reaction energy for $3 \mathbf{a}+\mathrm{H}^{+} \rightarrow 5 \mathbf{a}^{+\cdot}$ was adjusted by the difference in

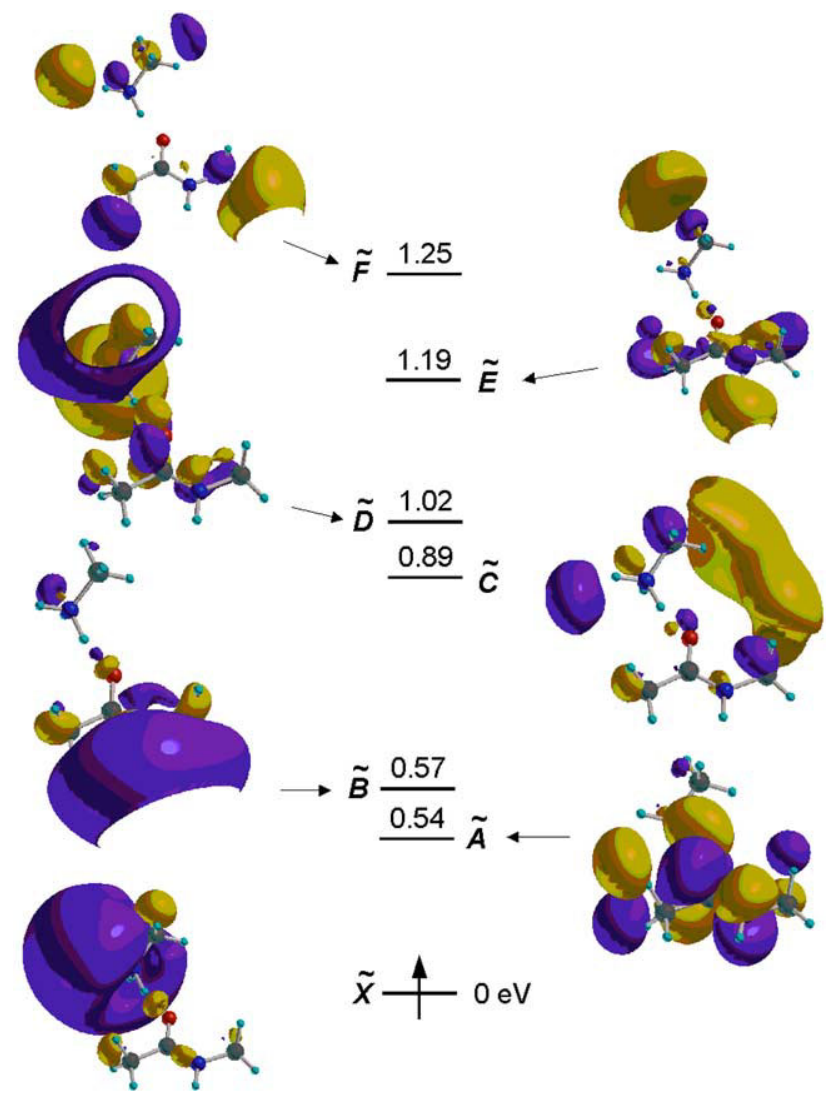

Figure 8. TD-B3LYP/aug-cc-pVTZ molecular orbitals for the $X$ through $\boldsymbol{F}$ electronic states of $\mathbf{3}$ after vertical electron attachment to $3^{+}$. Vertical excitation energies are in units of electron volts. 


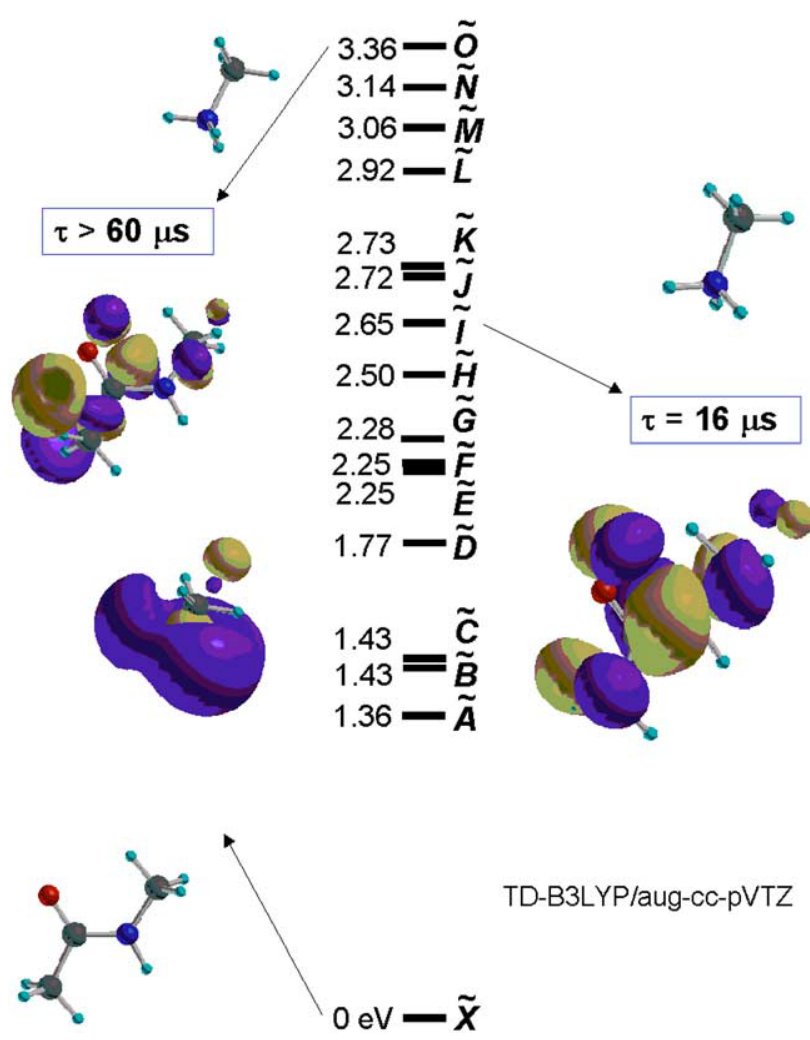

Figure 9. TD-B3LYP/aug-cc-pVTZ molecular orbitals for the $X$ through $\boldsymbol{F}$ electronic states of $3 \mathbf{a}$. Vertical excitation energies are in units of electron volts.

ZPVEs and $298 \mathrm{~K}$ thermal energies for the reactants and products, estimated as $21 \mathrm{~kJ} \mathrm{~mol}^{-1}$ from the $298 \mathrm{~K}$ enthalpy difference in $\mathbf{1}+\mathrm{H}^{+}$and $\mathbf{2}^{+}$to give the $298 \mathrm{~K}$ reaction enthalpy as $956 \mathrm{~kJ} \mathrm{~mol}^{-1}$. This was corrected for the excitation energy associated with charge rearrangement in $5 \mathrm{a}^{+\cdot}, \Delta E_{\text {exc }}(X \rightarrow A)=0.14 \mathrm{eV}$ from TD-B3LYP/aug-cc-pVTZ calculations, yielding a PA = $942 \mathrm{~kJ} \mathrm{~mol}^{-1}$ for the NMA moiety in 3a. By comparison, the PA of isolated 1 was previously reported as $893 \mathrm{~kJ}$ $\mathrm{mol}^{-1}$ (G2 value) [11]. Much of this difference is attributable to the stabilizing ion-dipole interaction between the $\mathrm{CH}_{3} \mathrm{NH}_{3}$ and 1-hydroxy-1-(N-methyl)aminomethyl moieties in $5 \mathrm{a}^{+\cdot}$. Intramolecular hydrogen atom transfer in the $X$ state of $3 a$ to produce the [1-hydroxy-1-(Nmethyl)aminomethyl radical...methylamine] system (6a) was calculated to be $38-40 \mathrm{~kJ} \mathrm{~mol}^{-1}$ exothermic, which is virtually the same as in the H-bonded system 3 (see above).

Of particular interest in $\mathbf{3 a}$ is the potential existence of excited electronic states which have high electron density in the amide group, thereby directing electron attachment to N-methylacetamide rather than methylammonium. Several such states were found by TDB3LYP calculations, two of which are shown in Figure 9. The $I$ state of $3 \mathrm{a}\left(\Delta E_{\mathrm{exc}}=2.65-2.76 \mathrm{eV}\right)$ bears a striking similarity to the $E$ state of point charge model $1 \mathrm{a}^{-*}\left(\Delta E_{\text {exc }}\right.$ $=1.85-2.47 \mathrm{eV}$ ) with substantial electron density delocalized over the amide group in an antibonding- $\pi$ orbital. The $\boldsymbol{O}$ state of $\mathbf{3 a}\left(\Delta E_{\text {exc }}=3.36-3.79 \mathrm{eV}\right)$ has an additional contribution from a $p$-type Rydberg orbital over the out-of-plane C-methyl hydrogens. Both of these states were calculated to have long radiative lifetimes (16 and $>60 \mu \mathrm{s}$ for the $\boldsymbol{I}$ and $\boldsymbol{O}$ states, respectively), making them relevant in terms of proton transfer kinetics.

Protonation of $\mathbf{3 a}$ in any of the electronic states described above results in direct generation of $5 \mathbf{a}^{+\cdot}$. As the reactant energies increase in the higher electronic states, with protonation leading to the same reaction product (the $X$ state of $5 \mathrm{a}^{+\cdot}$ ), so do proton affinities in higher excited states of $\mathbf{3 a}$. Correcting the $\mathbf{3 a}+\mathrm{H}^{+} \rightarrow$ $5 a^{+\cdot}$ reaction energies with the estimated difference in reactant and product ZPVEs and $298 \mathrm{~K}$ thermal enthalpies, as discussed above, yielded PA $=1170-1174$ and $1238-1270 \mathrm{~kJ} \mathrm{~mol}^{-1}$ for the $I$ and $O$ states of $3 \mathbf{a}$, respectively. Topical proton affinities for other sites in the NMA anion radical are expected to be substantially lower, for two reasons. First, selective O-protonation was previously calculated to be favored over N-protonation by $61 \mathrm{~kJ} \mathrm{~mol}^{-1}$ in isolated $\mathrm{N}$-methylacetamide [11]. Second, as shown by the NPA charge densities, enhanced polarization of the $\mathrm{C}=\mathrm{O}$ bond following electron attachment to the NMA moiety results in an increased negative atomic charge on oxygen. This negative charge would further favor selective O-protonation in a peptide ion, resulting in the generation of a reactive carbon-centered ketyl radical. Intramolecular proton transfer from the methylammonium to the amide moiety in the $\boldsymbol{I}$ and $\boldsymbol{O}$ states of $3 \mathrm{a}$ to produce $5 \mathrm{a}^{+}$. was calculated to be exothermic by 294 and $362 \mathrm{~kJ}$

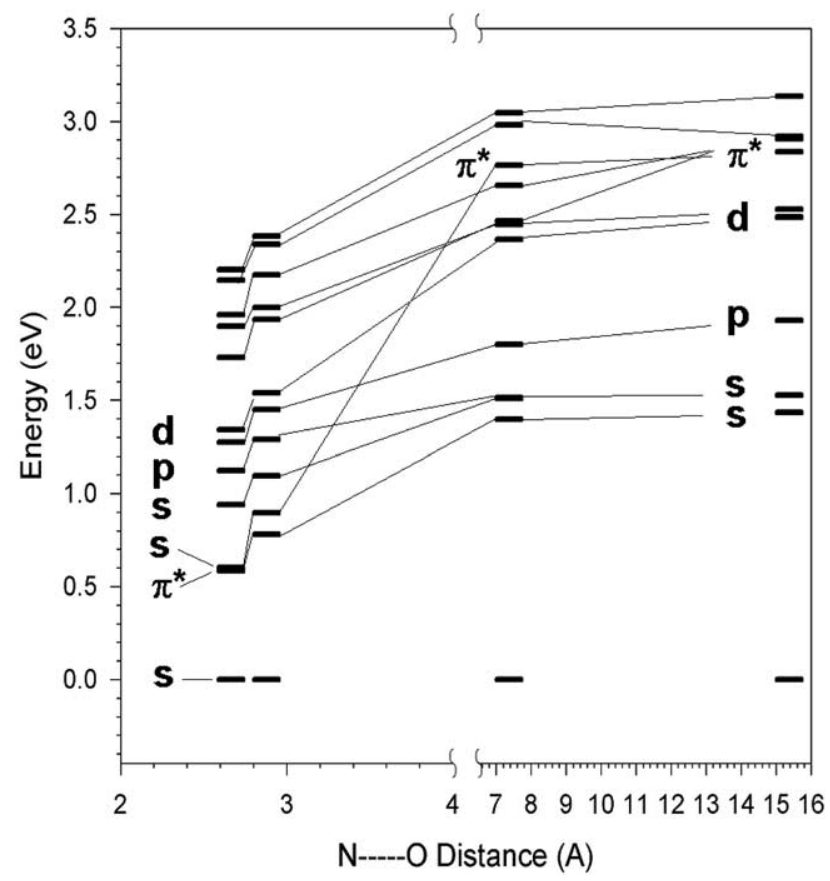

Figure 10. Excitation energies $(\mathrm{eV})$ in $\left[\mathrm{NMA} . \mathrm{CH}_{3} \mathrm{NH}_{3}\right]$ complexes at $\mathrm{O} \ldots \mathrm{N}$ distances corresponding to $3^{+}, 3,3 \mathrm{a}$, and $3 \mathrm{c}$ 
Table 5. [N-methylacetamide ... methylammonium] relative energies

\begin{tabular}{|c|c|}
\hline Species/reaction & Relative energy ${ }^{a}$ \\
\hline $3 \mathbf{a}^{+}$ & 11 \\
\hline $3 \mathbf{b}^{+}$ & 0 \\
\hline $5 \mathrm{a}^{+\cdot} \rightarrow(X) 3 \mathrm{a}+\mathrm{H}^{+}$ & $983(913)^{b}(914)^{b c}$ \\
\hline $5 \mathbf{a}^{+\cdot} \rightarrow(I) 3 \mathbf{a}+\mathrm{H}^{+}$ & $1174^{\mathrm{b}}(1170)^{\mathrm{bc}}$ \\
\hline $5 a^{+\cdot} \rightarrow(O) 3 a+H^{+}$ & $1270^{\mathrm{b}}(1238)^{\mathrm{bc}}$ \\
\hline$(X) 3 a \rightarrow 6 a$ & $-40(-38)^{\mathrm{c}}$ \\
\hline$(n) 3 a \rightarrow 6 a$ & $-301(-294)^{c}$ \\
\hline$(0) 3 a \rightarrow 6 a$ & $-397(-362)^{c}$ \\
\hline
\end{tabular}

In units of kilojoules per mole, uncorrected for ZPVEs, at B3LYP/6-311 $++\mathrm{G}(2 \mathrm{~d}, \mathrm{p})$.

bProton affinities of $7 \mathrm{a}$ at $298 \mathrm{~K}$, from ZPVE and thermal energy estimates as described in the text.

${ }^{\mathrm{C} F r o m ~ B 3 L Y P / a u g-c c-p V T Z ~ s i n g l e-p o i n t ~ e n e r g i e s ~}$

$\mathrm{mol}^{-1}$, respectively. The relative energies for the [NMA. . . $\mathrm{CH}_{3} \mathrm{NH}_{3}$ ] systems are summarized in Table 5.

Guanidinium charge models. Arginine has the most basic side group of all amino acid residues, and is readily protonated and internally solvated to backbone carbonyl groups in gas-phase peptide ions. As the charge carrier in protonated arginine, the guanidinium ion provides an appropriate chemical model of a neighboring charged group. Four [NMA. . guanidinium] orientations were investigated, in very similar fashion to the methylammonium systems discussed above. In two of the orientations, the nearest guanidinium nitrogen was fixed $7 \AA$ from the NMA oxygen, and the $\mathrm{O}-\mathrm{N}-\mathrm{C}$ angle was frozen at $180^{\circ}$. As before, the first of these conformations $\left(7 \mathbf{a}^{+}\right)$involved separately optimized guanidinium cation and NMA, oriented such that the $\mathrm{C}=\mathrm{O}-\mathrm{N}$ angle was $120^{\circ}$, and the guanidinium was in the plane of NMA $\left(\mathrm{N}-\mathrm{C}=\mathrm{O}-\mathrm{N}\right.$ dihedral angle $\left.=0^{\circ}\right)$ (Figure 11$)$. In the second system $\left(7 \mathbf{b}^{+}\right)$, the $\mathrm{O}-\mathrm{N}$ and $\mathrm{O}-\mathrm{N}-\mathrm{C}$ coordinates were frozen at $7 \AA$ and $180^{\circ}$, respectively, while allowing all remaining degrees of freedom to optimize. The guanidinium ion in $7 \mathbf{b}^{+}$was oriented such that the angle $\mathrm{C}=\mathrm{O}-\mathrm{N}$ was $173^{\circ}$, and the dihedral angle $\mathrm{N}-\mathrm{C}=\mathrm{O}-\mathrm{N}$ was $-55^{\circ}$. Conformation $7 \mathrm{c}^{+}$was identical to $7 \mathrm{a}^{+}$, except the guanidinium carbon, rather than nitrogen, was fixed $7 \AA$ from the NMA oxygen. This coordinate was frozen at $7 \AA$ in $7 \mathrm{~d}^{+}$as well, and optimization of the appropriate degrees of freedom was performed identically to the $7 \mathbf{b}^{+}$system. The guanidinium ion in $7 \mathrm{~d}^{+}$was oriented such that the angle $\mathrm{C}=\mathrm{O}-\mathrm{N}$ was $167^{\circ}$, and the dihedral angle $\mathrm{N}-\mathrm{C}=\mathrm{O}-\mathrm{N}$ was $-177^{\circ}$. Stabilization energies were calculated as 9 and $13 \mathrm{~kJ} \mathrm{~mol}^{-1}$ for $7 \mathbf{a}^{+} \rightarrow 7 \mathbf{b}^{+}$and $7 \mathrm{c}^{+}$ $\rightarrow 7 \mathrm{~d}^{+}$, respectively.

Vertical neutralization of ions $7 \mathrm{a}^{+}-7 \mathrm{~d}^{+}$produced nearly isoenergetic radicals, with $7 \mathrm{a}$ lower in energy than $7 \mathbf{b}$ by $0.2 \mathrm{~kJ} \mathrm{~mol}^{-1}$, and $7 \mathbf{d}$ lower in energy than $7 \mathrm{c}$ by $0.3 \mathrm{~kJ} \mathrm{~mol}^{-1}$. Vertical recombination energies by B3LYP/6-311 ++ G(2d,p) ranged from 3.39 to $3.56 \mathrm{eV}$ for ions $7 \mathbf{a}^{+}-\mathbf{7} \mathbf{d}^{+}$, as summarized in Table 4. Analogously to the methylammonium system, NPA charge and spin densities for the $X$ states of $7 \mathbf{a}$ and $7 \mathbf{a}^{+}$show reduction occurring exclusively in the guanidinium ion (Figure 11), while the NMA atomic charges are virtually identical to those calculated for the corresponding point charge models $\mathbf{1 a}$ and $\mathbf{1 \mathbf { a } ^ { + }}$. The $\boldsymbol{X}$ state SOMO of Radical 7a shows the unpaired electron primarily in diffuse orbitals around the guanidinium hydrogens (Figure 12). Generation of the [1-hydroxy-1-(N-methyl)aminomethyl radical. . guanidinium] cation system $\left(8 \mathbf{a}^{+\cdot}\right)$ by O-protonation in $\mathbf{7 a}$, followed by charge transfer, was calculated as being $1036 \mathrm{~kJ} \mathrm{~mol}^{-1}$ exothermic. As for $\mathbf{3 a}$, the intrinsic proton affinity of $7 \mathbf{a}$ was estimated by correcting the reaction energy above by the difference in estimated ZPVEs and $298 \mathrm{~K}$ thermal energies for the reactants and products, as well as the difference in adiabatic ionization energies for Radical $2(4.73 \mathrm{eV})$ and the guanidinium radical $(4.15 \mathrm{eV})$. This yielded a PA = $952 \mathrm{~kJ} \mathrm{~mol}^{-1}$ for 7a. Intramolecular hydrogen atom transfer from the guanidinium to the amide moiety in the $X$ state of $7 \mathbf{a}$ to produce the [1-hydroxy-1-(Nmethyl)aminomethyl radical. . guanidine] system (9a) was calculated to be $14 \mathrm{~kJ} \mathrm{~mol}^{-1}$ exothermic.

As in $3 \mathbf{a}$, excited electronic states of $7 \mathbf{a}$ involving electron attachment to NMA rather than the charged group were of interest. The molecular orbitals for two

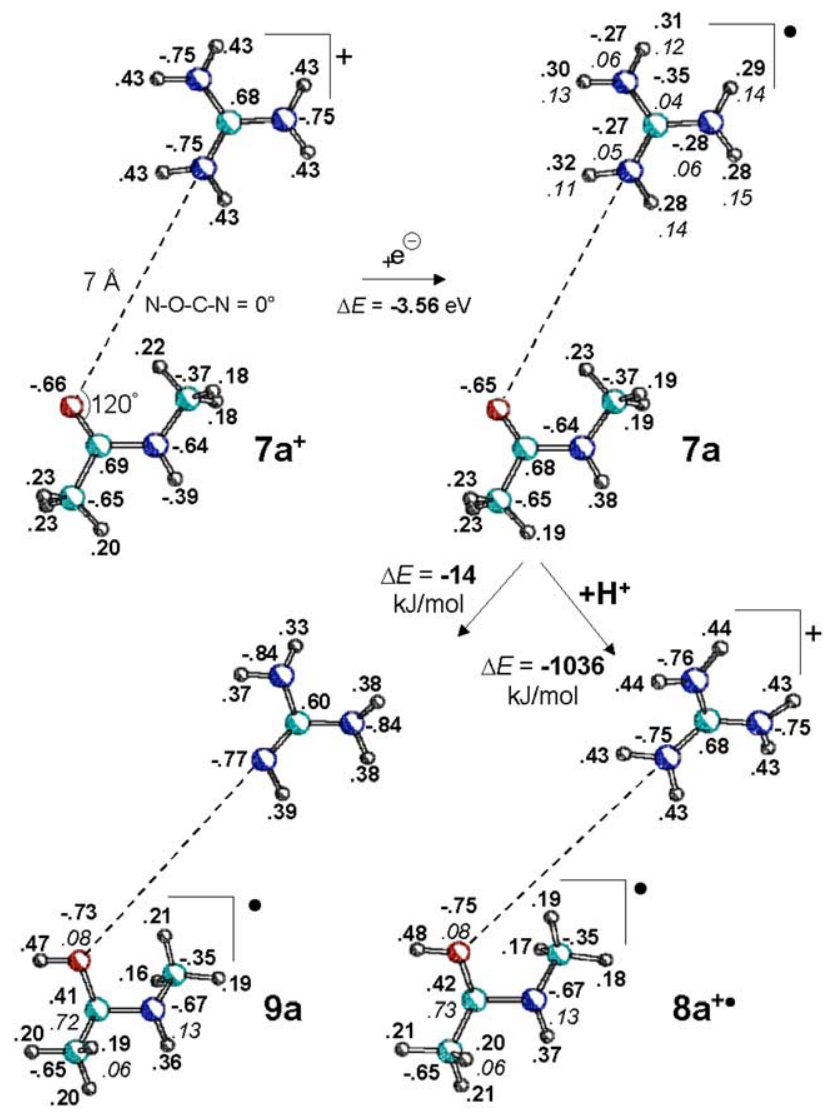

Figure 11. NPA charge and spin densities for $7 \mathbf{a}^{+}, \mathbf{7 a}, \mathbf{8} \mathbf{a}^{+}$, and 9a. Charge densities are in bold, and spin densities are in italics. Reaction energies are based on vertically-produced $7 \mathbf{a}$, and do not include ZPVE corrections. 


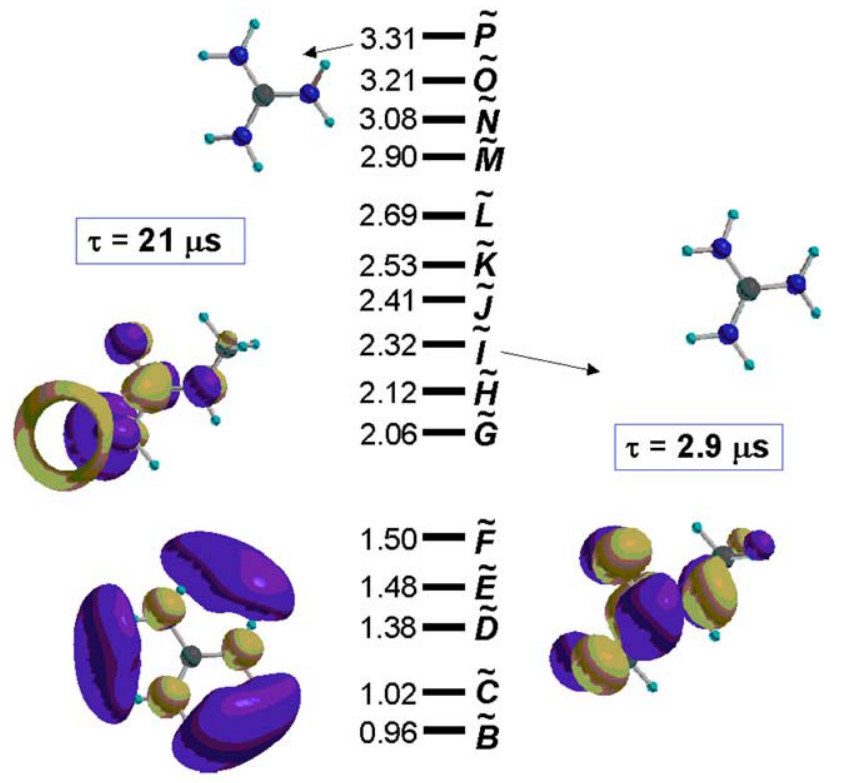

TD-B3LYP/6-311++g(2d,p)

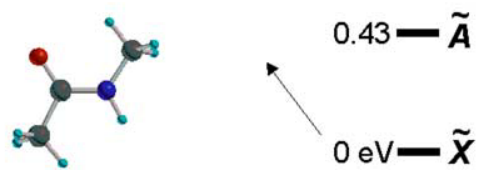

Figure 12. TD-B3LYP/6-311 ++ G(2d,p) molecular orbitals for the $X, I$, and $P$ states of $7 \mathbf{a}$. Vertical excitation energies are in units of electron volts.

such states, found by TD-B3LYP/6-311 + $+\mathrm{G}(2 \mathrm{~d}$, p), are shown in Figure 12. The $I$ state of $7 \mathrm{a}\left(\Delta E_{\text {exc }}=2.32 \mathrm{eV}\right)$ carries delocalized electron density in an antibonding- $\pi$ orbital over the amide group, in virtually identical fashion as the above-mentioned $\boldsymbol{I}$ state of $\mathbf{3 a}$ and the $\boldsymbol{E}$ state of point charge model $\mathbf{1 a}^{-}$. Additionally, the $\boldsymbol{P}$ state of $7 \mathbf{a}\left(\Delta E_{\text {exc }}=3.31 \mathrm{eV}\right)$ includes a $p$-type Rydberg orbital over the out-of-plane C-methyl hydrogens, just as in the $\boldsymbol{O}$ state of $\mathbf{1 a}$. The $\boldsymbol{I}$ and $\boldsymbol{P}$ states in $\mathbf{7 a}$ were calculated to have radiative lifetimes of 2.9 and $21 \mu \mathrm{s}$, respectively. The sums of atomic charge densities (NPA) for the NMA and guanidinium moieties were calculated as -0.90 and +0.90 , respectively, again characterizing the electronic structure of this state as a decoupled anion radical. . .cation system. Proton affinities of the $\boldsymbol{I}$ and $\boldsymbol{O}$ states of $\mathbf{7 a}$ were calculated as PA $=1239$ and $1334 \mathrm{~kJ} \mathrm{~mol}^{-1}$, respectively. Intramolecular proton transfer in the $\boldsymbol{I}$ and $\boldsymbol{P}$ states of $7 \mathrm{a}$ to produce $9 \mathrm{a}$ was calculated to be exothermic by 237 and $333 \mathrm{~kJ} \mathrm{~mol}^{-1}$, respectively. Relative energies for the [NMA. . guanidinium] systems are summarized in Table 6.

\section{Discussion}

The computational results presented above reveal several new features for the species produced by electron capture. First, in hypervalent ammonium radicals, as represented by $\mathrm{CH}_{3} \mathrm{NH}_{3}$, the point charge mainly affects the properties of the ground electronic state, which gains or loses stability depending on the point charge position. The properties of the excited states are much less affected; in particular, the excited states are strongly bound along the $\mathrm{N}-\mathrm{H}$ dissociation coordinate regardless of the point charge distance or orientation. This finding is consistent with the results of a recent study in which a charged ammonium group was placed in the vicinity of a hypervalent ammonium group on the cyclopentane ring [16].

Second, the point charge has a substantial effect on the properties of the amide group, as modeled by the $\mathrm{N}$-methylacetamide system (1a). Electron capture in this system is predicted to produce long lived electronic states of the charge-reduced system $\left(\mathbf{1 a}^{-}\right)$. However, direct bond cleavage in this charge-reduced system is substantially endothermic, even more so than in the absence of charge. This indicates that direct amide bond cleavage in charge-reduced peptides may not be facilitated by the presence of a charge carried by a remote protonated amino acid residue. In contrast, we find $\mathbf{1 a}^{-}$. to have a large proton affinity $\left(1027 \mathrm{~kJ} \mathrm{~mol}^{-1}\right)$ that makes the amide group an extremely strong base. The proton affinity increases as the charge is removed farther from the amide group, reaching a limit of 1265 $\mathrm{kJ} \mathrm{mol}{ }^{-1}$ in excited states of $1 \mathrm{a}^{--}$. This implies that the superbasic amide carbonyl in a charge-reduced peptide cation-radical can exothermically abstract a proton from any protonated amino acid residue, including lysine and arginine. Proton transfer onto the amide group in $1 \mathrm{a}^{-\cdot}$ generates a labile aminoketyl radical that can undergo $\mathrm{N}-\mathrm{C}_{\alpha}$ bond dissociation, for which very low energy barriers have been calculated recently [11, $14,15]$.

Third, the calculations of electron capture by amide bonds in the presence of methylammonium and guanidinium charge carriers point to the importance of excited electronic states. These are very closely spaced within the energy interval limited by the ionization energy of the guanidinium or ammonium radicals $(3.5-4.2 \mathrm{eV})$ and some show long

Table 6. [N-methylacetamide. . guanidinium] relative energies

\begin{tabular}{|c|c|}
\hline Species/reaction & Relative energy \\
\hline $7 a^{+}$ & 16 \\
\hline $7 b^{+}$ & 8 \\
\hline $7 c^{+}$ & 13 \\
\hline $7 d^{+}$ & 0 \\
\hline $8 \mathrm{a}^{+\cdot} \rightarrow(X) 7 \mathrm{a}+\mathrm{H}^{+}$ & 1036 \\
\hline $8 \mathbf{a}^{+\cdot} \rightarrow(I) 7 \mathrm{a}+\mathrm{H}^{+}$ & $1239^{b}$ \\
\hline $8 a^{+\cdot} \rightarrow(0) 7 a+H^{+}$ & $1334^{\mathrm{b}}$ \\
\hline$(X) 7 \mathrm{a} \rightarrow 9 \mathrm{a}$ & -14 \\
\hline (I)7a $\rightarrow 9 a$ & -237 \\
\hline$(0) 7 a \rightarrow 9 a$ & -333 \\
\hline
\end{tabular}

an units of kilojoules per mole, uncorrected for ZPVEs, at B3LYP/6-311 $++\mathrm{G}(2 \mathrm{~d}, \mathrm{p})$.

bProton affinities of $7 a$ at $298 \mathrm{~K}$, from ZPVE and thermal energy estimates as described in the text. 

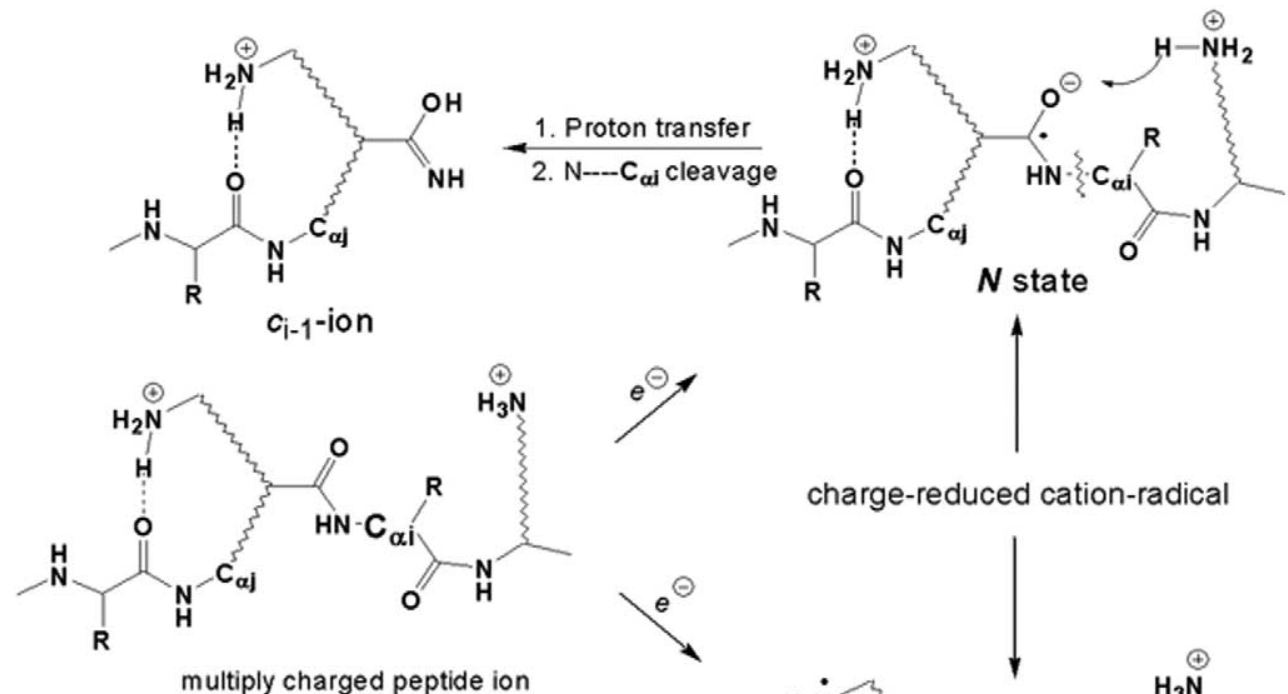

charge-reduced cation-radical
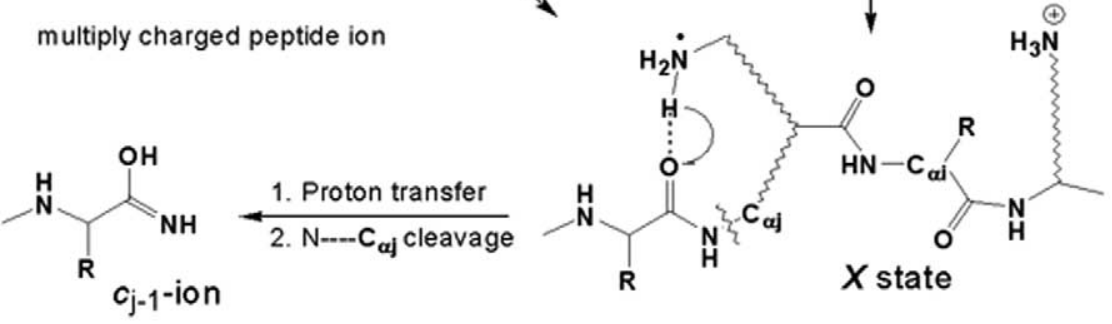

Scheme 2. General mechanism for ECD in ground and excited electronic states of peptide ions.

radiative lifetimes. We find several long-lived excited states in which the amide carbonyl group incurs a proton affinity exceeding $1200 \mathrm{~kJ} \mathrm{~mol}^{-1}$, which is more than sufficient to abstract a proton from any protonated amino acid residue, again forming a labile aminoketyl radical. The importance of excited states has been postulated previously [20,23], although it was speculated that dissociative excited states lead to amide bond dissociation. The present results indicate that some long-lived excited states are superbases that can be involved in proton transfer in chargereduced peptides following electron capture.

The new results allow us to unify the mechanisms for peptide bond cleavage by ECD of multiplycharged ions, as depicted in Scheme 2. Electron capture is presumed to occur by a cascade process $[17,24]$ where a number of electronic states of the incipient charge-reduced ion are sampled consecutively. The ground state of the charge-reduced system corresponds to an ammonium or guanidinium radical, depending on the type of charge-carrying amino acids that have the highest recombination energies. If the ground state of an ammonium radical (lysine or $\mathrm{N}$-terminus) is reached, a hydrogen atom can be transferred from the ammonium group onto a proximate amide carbonyl. Because of the competition between $\mathrm{H}$-atom loss and transfer, the latter is favored when occurring at an internally solvated amide carbonyl. This explains why hydrogen transfer in ECD does not occur at the carbonyl carbon atom, despite practically identical transition state energies for $\mathrm{H}$ atom addition to the carbonyl $\mathrm{C}$ and $\mathrm{O}$ termini [10, 11]. Also noteworthy is the nature of the $\mathrm{H}$ atom transfer, which has been shown to follow the protoncoupled electron transfer mechanism in which the proton and electron migrations occur in different regions of space and with different timing [13]. Clearly, this part of the overall mechanism explains $\mathrm{N}-\mathrm{C}_{\alpha}$ bond dissociations in the vicinity of the charge-carrying residue. This is consistent with recent ECD studies of model doubly- and triplycharged peptides that found that bond cleavages occur preferentially in the vicinity of lysine charge carriers [56].

The apparently less discriminate dissociation of $\mathrm{N}-\mathrm{C}_{\alpha}$ bonds that do not belong to the internally solvated amide groups is explained by the reactivity of the excited electronic states formed by electron capture. The amide bonds in some of these electronic states acquire substantial electron density that makes them superbasic and reactive toward exothermically abstracting a proton from an accessible site. The latter proton transfer may necessitate a conformational change in the charge-reduced peptide ion that can be driven by attractive coulomb interactions between the negatively charged amide group and a protonated lysine or guanidine group, or by ion-dipole interactions with other amide groups in the ion. According to our calculations, the radiative lifetimes of the pertinent excited electronic states are long enough to allow both conformational motion of the peptide backbone and amino acid side chains and fast intramolecular proton transfer that 
requires only low vibrational excitation in the transition state [13]. Note in this context that long lifetimes, radiative and/or non-radiative, on the order of microseconds were previously reported for charge-reduced ammonium radicals in a study that used laser photoexcitation [40]. Proton transfer onto the amide carbonyl in an excited electronic state (labeled arbitrarily $N$ in Scheme 2) produces a fragile aminoketyl radical that can undergo facile cleavage of the adjacent $\mathrm{N}-\mathrm{C}_{\alpha}$ bond. An attractive feature of the new amide-base mechanism is that it does not require that the ionizing proton be transferred to the amide carbonyl, and thus this mechanism is applicable to ECD of multiply charged ions in which the charge is introduced as sodium or other metal ion, or as a quaternary ammonium group [18]. We have shown previously that peptide coordination to metal ions greatly increases the acidity of $\mathrm{C}_{\alpha}$ protons that can be the potential target for transfer onto a basic amide group in an excited electronic state of the charge-reduced peptide cation [57]. This new mechanism is also consistent with recent reports of substantial hydrogen scrambling upon ECD of peptide dications that involved protons from $\alpha$-methylene groups in glycine residues [58]. According to our mechanism, the sterically accessible glycine $\alpha$-protons are a prime target for reversible transfer to a superbasic amide group in the particular electronic state of a charge-reduced peptide ion.

The amide-superbase mechanism can be particularly important in ECD of arginine-containing peptides. According to our concurrent calculations [59], the charged guanidinium group in protonated arginine is much less effectively internally solvated by the backbone amide group than is the lysine ammonium group. In addition, hydrogen atom transfer from the reduced guanidinium group to the amide carbonyl is endothermic and requires substantial energy $\left(>70 \mathrm{~kJ} \mathrm{~mol}^{-1}\right)$ in the transition state. These features increase the stability of the $X$ state in arginine containing peptide cation-radicals, and indicate that an increased proportion of electron capture dissociations may occur from excited electronic states via the amide-superbase mechanism.

It may be noted that the amide-superbase mechanism is not fundamentally different from that in Scheme 1 which presumes hydrogen atom transfer in the ground electronic state of a radical formed by electron capture in an internally solvated peptide ion. According to the previous analysis of electronic properties of such charge-reduced species, the hydrogen atom transfer can be described by the proton-coupled electron transfer [13] where the migrating species is a proton.

\section{Conclusions}

The computational study of electron capture by ammonium and amide groups in the presence of remote positive charge allows us to arrive at the following conclusions. In the presence of a remote charge, the amide group can exothermically capture an electron in a long-lived electronic state of a valence type. Electron capture by the amide group increases the basicity of the amide carbonyl oxygen that can exothermically abstract a proton from an amino acid residue, thus forming a labile aminoketyl radical that dissociates readily by $\mathrm{N}-\mathrm{C}_{\alpha}$ bond cleavage. This mechanism explains why peptide dissociations upon ECD show low positional selectivity and why electron capture induces efficient $\mathrm{N}-\mathrm{C}_{\alpha}$ bond cleavage in systems that lack ammonium and guanidinium groups as hydrogen atom donors. The new mechanism allows us to provide a uniform description of the formation of aminoketyl radicals as key transient intermediates in ECD.

\section{Acknowledgments}

The authors gratefully acknowledge support of this research by the National Science Foundation (grant CHE-0349595). The Computational Facility at the Department of Chemistry was supported jointly by NSF (grant CHE-0342956) and the University of Washington. EAS thanks the Alma and Lloyd West Graduate Fellowship for support in the course of this work.

\section{References}

1. Biemann, K. Peptides and Proteins Overview and Strategy. Meth. Enzymol. (McCloskey, J. A., Ed.) 1990, 193, 351-360.

2. Busch, K. L.; Glish, G. L.; McLuckey, S. A. Mass Spectrometry/ Mass Spectrometry. Techniques and Applications of Tandem Mass Spectrometry; VCH Publishers: New York, 1988, pp 248-265.

3. Woodin, R. L.; Bomse, D. S.; Beauchamp, J. L. Multiphoton Dissociation of Molecules with Low Power Continuous Wave Infrared Laser Radiation. J. Am. Chem. Soc. 1978, 100, 32483250 .

4. (a) Gatlin, C. L.; Rao, R. D.; Tureček, F.; Vaisar, T. Carboxylate and Amine Terminus Directed Fragmentations in Gaseous Dipeptide Complexes with Copper(II) and Diimine Ligands Formed by Electrospray. Anal. Chem. 1996, 68, 263-270. (b) Vaisar, T.; Gatlin, C. L.; Rao, R. D.; Seymour, J. L.; Tureček, F. Sequence Information, Distinction, and Quantitation of CTerminal Leucine and Isoleucine in Ternary Complexes of Tripeptides with $\mathrm{Cu}(\mathrm{II})$ and 2,2'-Bipyridine. J. Mass Spectrom. 2001, 36, 306-316.

5. (a) Chu, I. K.; Rodriguez, C. F.; Lau, T. C.; Hopkinson, A. C.; Siu, K. W. M. Molecular Radical Cations of Oligopeptides. J. Phys. Chem. B 2000, 104, 3393-3397. (b) Bagheri-Majdi, E.; Ke, Y.; Orlova, G.; Chu, I. K.; Hopkinson, A. C.; Siu, K. W. M. Copper-Mediated Peptide Radical Ions in the Gas Phase. J. Phys. Chem. B 2004, 108, 11170-11181.

6. Rowe, B. R.; Mitchell, J. B.; Canosa, A, Eds.; In Dissociative Recombination. Theory, Experiment, and Applications; Plenum Press: New York, 1993.

7. Zubarev, R. A.; Kelleher, N. L.; McLafferty, F. W. Electron Capture Dissociation of Multiply Charged Protein Cations. A Nonergodic Process. J. Am. Chem. Soc. 1998, 120, 3265-3266.

8. Kruger, N. A.; Zubarev, R. A.; Carpenter, B. K.; Kelleher, N. L.; Horn, D. M.; McLafferty, F. W. Electron-Capture Dissociation of Multiply Charged Peptide Cations, Int. J. Mass Spectrom. 1999, 183, 1-5.(a) McLafferty, F. W.; Horn, D. M.; Breuker, K.; Ge, Y.; Lewis, M. A.; Cerda, B.; Zubarev, R. A.; Carpenter, B. K. Electron Capture Dissociation of Gaseous Multiply Charged Ions by Fourier-Transform Ion Cyclotron Resonance. J. Am. Soc. Mass Spectrom. 2001, 12, 245-249. (b) Zubarev, R. A.; Haselmann, K. F.; Budnik, B.; Kjeldsen, F.; Jensen, F. Towards an Understanding of the Mechanism of Electron-Capture 
Dissociation: A Hhistorical Perspective and Modern Ideas. Eur. J. Mass Spectrom. 2002, 8, 337-349. (c) Zubarev, R. A. Reactions of Polypeptide Ions in the Gas Phase. Mass Spectrom. Re. 2003, 22, 57-77.

9. (a) Cooper, H. J.; Hudgins, R. R.; Hakansson, K.; Marshall, A. G. Secondary Fragmentation of Linear Peptides in Electron Capture Dissociation. Int. J. Mass Spectrom. 2003, 228, 723-728. (b) Kjeldsen, F.; Zubarev, R. Secondary Losses via $\gamma$-Lactam Formation in Hot Electron Capture Dissociation: A Missing Link to Complete de Novo Sequencing of Proteins? J. Am. Chem. Soc. 2003, 125, 6628-6629. (c) Leymarie, N.; Costello, C. E.; O'Connor, P. B. Electron Capture Dissociation Initiates a Free Radical Reaction Cascade. J. Am. Chem. Soc. 2003, 125, 8949-8958.

10. Syrstad, E. A.; Tureček, F. Hydrogen Atom Adducts to the Amide Bond. Generation and Energetics of the Amino(Hydroxy)Methyl Radical in the Gas Phase J. Phys. Chem. A 2001, 105, 11144-11155.

11. Syrstad, E. A.; Stephens, D. D.; Tureček, F. Hydrogen Atom Adducts to the Amide Bond. Generation and Energetics of Amide Radicals in the Gas Phase. J. Phys. Chem. A 2003, 107, 115-126.

12. Konishi, H. Yokotake, Y. Ishibashi, T. Theoretical Study on the Electron Capture Dissociation Correlated with Proton Transfer Processes.J. Mass Spectrom. Soc. Jpn. 2002, 50, 222-225.

13. Tureček, F.; Syrstad, E. A. Mechanism and Energetics of Intramolecular Hydrogen Transfer Atom Transfer in Amide and Peptide Radicals and Cation-Radicals J. Am. Chem. Soc. 2003, 125, 3353-3369.

14. Tureček, $\mathrm{F} . \mathrm{N}-\mathrm{C}_{\alpha}$ Bond Dissociation Energies and Kinetics in Amide and Peptide Radicals. Is the Dissociation a NonErgodic Process? J. Am. Chem. Soc. 2003, 125, 5954-5963.

15. Tureček, F.; Syrstad, E. A.; Seymour, J. L.; Chen, X.; Yao, C. Peptide Cation-Radicals. A Computational Study of the Competition Between Peptide $\mathrm{N}-\mathrm{C}_{\alpha}$ Bond Cleavage and Loss of the Side Chain in the [GlyPhe- $\left.\mathrm{NH}_{2}+2 \mathrm{H}\right]^{+}$Cation Radical. J. Mass Spectrom. 2003, 38, 1093-1104.

16. Tureček, F. Stereochemical Interactions in Ammonium Dications, Hypervalent Diammonium Cation-Radicals, and Ammonium Radicals. A B3-MP2 Computational Study. Eur. J. Mass Spectrom. 2003, 9, 267-277.

17. Sawicka, A.; Skurski, P.; Hudgins, R. R.; Simons, J. Model Calculations Relevant to Disulifde Bond Cleavage via Electron Capture Influenced by Positively Charged Groups. J. Phys. Chem. B 2003, 107, 13505-13511.

18. Hudgins, R.R., Hakansson, K., Quinn, J.P.; Hendrickson,C. L.; Marshall, A.G. Electron Capture Dissociation of Peptides and Proteins Does Not Require a Hydrogen Atom Mechanism; Proceedings of the 50th ASMS Conference on Mass Spectrometry and Allied Topics; Orlando, FL, June, 2002; A020420.

19. Mihalca, R.; Kleinnijenhuis, A. J.; McDonnell, L. A.; Heck, A. J. R.; Heeren, R. M. A; Electron Capture Dissociation at Low Temperatures Reveals Selective Dissociations. J. Am. Soc. Mass Spectrom. 2004, in press.

20. Breuker, K.; Oh, H.-B.; Lin, C.; Carpenter, B. K.; McLafferty, F. W. Nonergodic and Conformational Control of the Electron Capture Dissociation of Protein Cations. Proc. Natl. Acad. Sci. U.S.A. 2004, 101, 14011-14016.

21. Demirev, P. A. Generation of Hydrogen Radicals for Reactivity Studies in Fourier Transform Ion Cyclotron Resonance Mass Spectrometry. Rapid. Commun. Mass Spectrom. 2000, 14, 777-781.

22. Bakken, V.; Helgaker, T.; Uggerud, E. Mechanism of Electron Capture Dissociation of Protonated Peptides. Presented at the 18th International Mass Spectrometry Conference; Edinburgh, August, 2003; Poster ThL-001.
23. Zubarev, R. A.; Horn, D. M.; Fridriksson, E. K.; Kelleher, N. L.; Kruger, N. A.; Lewis, M. A.; Carpenter, B. K.; McLafferty, F. W. Electron Capture Dissociation for Structural Characterization of Multiply Charged Protein Cations. Anal. Chem. 2000, 72, 563-573.

24. Bates, D. R. Dissociative Recombination. Phys. Rev. 1950, 78, 492-493.

25. Ketvirtis, A. E.; Simons, J. Dissociative Recombination of $\mathrm{H}_{3} \mathrm{O}^{+}$. J. Phys. Chem. A 1999, 103, 6552-6563.

26. Bardsley, J. N. Theory of Dissociative Recombination. J. Phys. B 1968, 1, 365-380.

27. (a) Frisch, M. J., Trucks, G. W., Schlegel, H. B., Scuseria, G. E., Robb, M. A., Cheeseman, J. R., Zakrzewski, V. G., Montgomery, J. A., Stratmann, R. E., Burant, J. C., Dapprich, S., Millam, J. M., Daniels, A. D., Kudin, K. N., Strain, M. C., Farkas, O., Tomasi, J., Barone, V., Cossi, M., Cammi, R., Mennucci, B., Pomelli, C., Adamo, C., Clifford, S., Ochterski, J., Petersson, G. A., Ayala, P. Y., Cui, Q., Morokuma, K., Malick, D. K., Rabuck, A. D., Raghavachari, K., Foresman, J. B., Cioslowski, J., Ortiz, J. V., Stefanov, B. B., Liu, G., Liashenko, A., Piskorz, P., Komaromi, I., Gomperts, R., Martin, R. L., Fox, D. J., Keith, T., Al-Laham, M. A., Peng, C. Y., Nanayakkara, A., Gonzalez, C., Challacombe, M., Gill, P. M. W., Johnson, B. G., Chen, W., Wong, M. W., Andres, J. L., Head-Gordon, M., Replogle, E. S., Pople, J. A. Gaussian 98, Revision A.6; Gaussian, Inc., Pittsburgh, PA; 1998. (b) Frisch, M. J., Trucks, G. W., Schlegel, H. B., Scuseria, G. E., Robb, M. A., Cheeseman, J. R., Montgomery, J. A., Vreven, T., Kudin, K. N., Burant, J. C., Millam, J. M., Iyengar, J., Tomasi, J., Barone, V., Mennucci, B., Cossi, M., Scalmani, G., Rega, N., Petersson, G. A., Nakatsuji, H., Hada, M., Ehara, M., Toyota, K., Fukuda, R., Hasegawa, J., Ishida, M., Nakajima, T., Honda, Y., Kitao, O., Nakai, H., Klene, M., Li, X., Knox, J. E., Hratchian, H. P., Cross, J. B., Adamo, C., Jaramillo, J., Gomperts, R., Strattman, R. E., Yazyev, O., Austin, A. J., Cammi, R., Pomelli, C., Ochterski, J. W., Ayala, P. Y., Morokuma, K., Voth, G. A., Salvador, P., Dannenberg, J. J., Zakrzewski, V. G., apprich, S., Daniels, A. D., Strain, M. C., Farkas, O., Malick, D. K., Rabuck, A. D., Raghavachari, K., Foresman, J. B., Ortiz, J. V., Cui, Q., Baboul, A. G., Clifford, S., Cioslowski, J., Stefanov, B. B., Liu, G., Liashenko, A., Piskorz, P., Komaromi, I., Martin, R. L., Fox, D. J., Keith, T., Al-Laham, M. A., Peng, C. Y., Nanayakkara, A., Challacombe, M., Gill, P. M. W., Johnson, B., Chen, W., Wong, M. W., Gonzalez, C., Pople, J. A. Gaussian 03, Revision B.05, Gaussian, Inc., Pittsburgh, PA; 2003.

28. (a) Becke, A. D. A New Mixing of Hartree-Fock and Local Density-Functional Theories. J. Chem. Phys. 1993, 98, 13721377. (b) Becke, A. D. Density Functional Thermochemistry. III. The Role of Exact Exchange. J. Chem. Phys. 1993, 98, $5648-5652$.

29. Reed, A. E.; Weinstock, R. B.; Weinhold, F. Natural Population Analysis. J. Chem. Phys. 1985, 83, 735-746.

30. Dunning, T. H. Jr. Gaussian Basis Sets for Use in Correlated Molecular Calculations. I. The Atoms Boron through Neon and Hydrogen. J. Chem. Phys. 1989, 90, 1007-1023.

31. Curtiss, L. A.; Raghavachari, K.; Pople, J. A. Gaussian-2 Theory Using Reduced Moller-Plesset Orders. J. Chem. Phys. 1993, 98, 1293-1298.

32. Pople, J. A.; Head-Gordon, M.; Raghavachari, K. Quadratic Configuration Interaction. A General Technique for Determining Electron Correlation Energies. J. Chem. Phys. 1987, 87, 5968-5975.

33. (a) Tureček, F. Proton Affinity of Dimethyl Sulfoxide and Relative Stabilities of $\mathrm{C}_{2} \mathrm{H}_{6} \mathrm{OS}$ Molecules and $\mathrm{C}_{2} \mathrm{H}_{7} \mathrm{OS}^{+}$Ions. A Comparative G2(MP2) ab Initio and Density Functional Theory Study. J. Phys. Chem. A, 1998, 102, 4703-4713. (b) Tureček, F.; Wolken, J. K. Dissociation Energies and Kinetics of Amin- 
opyrimidinium Radicals by ab Initio and Density Functional Theory. J. Phys. Chem. A. 1999, 103, 1905-1912. (c) Tureček, F.; Polášek, M.; Frank, A. J.; Sadílek, M. Transient Hydrogen Atom Adducts to Disulfides. Formation and Energetics. J. Am. Chem. Soc. 2000, 122, 2361-2370. (d) Polášek, M.; Tureček, F. Hydrogen Atom Adducts to Nitrobenzene. Formation of the Phenylnitronic Radical in the Gas Phase and Energetics of Wheland Intermediates. J. Am. Chem. Soc. 2000, 122, 9511-9524.

34. Č́žžek, J.; Paldus, J.; Šroubková, L. Cluster Expansion Analysis for Delocalized Systems. Int. J. Quantum Chem. 1969, 3, 149167.

35. Purvis, G. D., III; Bartlett, R. J. A Full Coupled-Cluster Singles and Doubles Model: The Inclusion of Disconnected Triples. J. Chem. Phys. 1982, 76, 1910-1918.

36. (a) Schlegel, H. B. Potential Energy Curves Using Unrestricted Moller-Plesset Perturbation Theory with Spin Annihilation. J. Chem. Phys. 1986, 84, 4530-4534. (b) Mayer, I. Spin-Projected UHF Method. IV. Comparison of Potential Curves Given by Different One-Electron Methods. Adv. Quantum Chem. 1980, 12, 189-262.

37. Stratmann, R. E.; Scuseria, G. E.; Frisch, M. J. An Efficient Implementation of Time-Dependent Density Functional Theory for the Calculation of Excitation Energies of Large Molecules. J. Chem. Phys. 1998, 109, 8218-8224.

38. Foresman, J. B.; Head-Gordon, M.; Pople, J. A.; Frisch, M. J. Toward a Systematic Molecular Orbital Theory for Excited States. J. Phys. Chem. 1992, 96, 135-149.

39. Gellene, G. I.; Cleary, D. A.; Porter, R. F. Stability of the Ammonium and Methylammonium Radicals from Neutralized Ion-Beam Spectroscopy. J. Chem. Phys. 1982, 77, 34713477.

40. Nguyen, V. Q.; Sadílek, M.; Ferrier, J. G.; Frank, A. J.; Tureček, F. Metastable States of Dimethylammonium Radical. J. Phys. Chem. A 1997, 101, 3789-3799.

41. Shaffer, S. A.; Tureček, F. Hydrogentrimethylammonium. A Marginally Stable Hypervalent Radical. J. Am. Chem. Soc. 1994, 116, 8647-8653.

42. Shaffer, S. A.; Tureček, F. Hydrogen Bonding in Bifunctional Hypervalent Ammonium and Oxonium Radicals. J. Am. Soc. Mass Spectrom. 1995, 6, 1004-1018.

43. Shaffer, S. A.; Sadílek, M.; Tureček, F. Hypervalent Ammonium Radicals. Effects of Alkyl Groups and Aromatic Substituents. J. Org. Chem. 1996, 61, 5234-5245.

44. Wolken, J. K.; Nguyen, V. Q.; Tureček, F. Bond Dissociations in Hypervalent Ammonium Radicals Prepared by Collisional Neutralization of Protonated Six-Membered Nitrogen Heterocycles. J. Mass Spectrom. 1997, 32, 1162-1169.

45. Shaffer, S. A.; Wolken, J. K.; Tureček, F. NeutralizationReionization of Alkenylammonium CationsAn Experimental and ab Initio Study of Intramolecular $\mathrm{N}-\mathrm{H}$. . . C = C Interactions in Cations and Hypervalent Ammonium Radicals. J. Am. Soc. Mass Spectrom. 1997, 8, 1111-1123.

46. Frøsig, L.; Tureček, F. Hypervalent Pyrrolidinium Radicals by Neutralization-Reionization Mass Spectrometry. Metastability and Radical Leaving Group Abilities. I. Am. Soc. Mass Spectrom. 1998, 9, 242-254.

47. Boldyrev, A. I.; Simons, J. Theoretical Search for Large Rydberg MoleculesMethyl Derivatives of Ammonium Radical $\left[\mathrm{NH}_{3} \mathrm{CH}_{3}, \mathrm{NH}_{2}\left(\mathrm{CH}_{3}\right)_{2}, \mathrm{NH}\left(\mathrm{CH}_{3}\right)_{3}\right.$, and $\left.\mathrm{N}\left(\mathrm{CH}_{3}\right)_{4}\right]$. J. Chem. Phys. 1992, 97, 6621-6627.

48. Okai, N.; Takahata, A.; Fuke, K. Electronic Structure, Stability, and Formation Dynamics of Hypervalent Molecular Clusters $\mathrm{CH}_{3} \mathrm{NH}_{3}\left(\mathrm{CH}_{3} \mathrm{NH}_{2}\right)_{n}$. Chem. Phys. Lett. 2004, 386, 442447.

49. Yao, C.; Tureček, F. Hypervalent Ammonium Radicals. Competitive $\mathrm{N}-\mathrm{C}$ and $\mathrm{N}-\mathrm{H}$ Bond Dissociations in Methylammonium and Ethylammonium; unpublished.

50. Hendricks, J. H.; Lyapustina, S. A.; de Clercq, H. L.; Bowen, K. H. The Dipole Bound-to-Covalent Anion Transformation in Uracil. J. Chem. Phys. 1998, 108, 8-11.

51. Rao, D. N. R.; Symons, M. C. R.; Stephenson, J. M. RadiationInduced Electron Capture by Proteins Containing Disulfide Linkages: An Electron Spin Resonance Study. J. Chem. Soc. Perkin Trans. 21983, 727-730.

52. Stryer, L. Biochemistry; W. H. Freeman and Company: New York, 1975; p 34

53. Hunter, E. P.; Lias, S. G. Evaluated Gas Phase Basicities and Proton Affinities of MoleculesAn Update. J. Phys. Chem. Ref. Data 1998, 27, 413-656.

54. Harrison, A. G. The Gas-Phase Basicities and Proton Affinities of Amino Acids and Peptides. Mass. Spectrom. Rev. 1997, 16, 201-217.

55. Tureček, F.; Reid, P. J. Metastable States of Dimethyloxonium, $\left(\mathrm{CH}_{3}\right)_{2} \mathrm{OH}$. Int. J. Mass Spectrom. 2003, 222, 49-61.

56. (a) Chan, T.-W. D.; Ip, W. H. H. Optimization of Experimental Parameters for Electron Capture Dissociation of Peptides in a Fourier Transform Mass Spectrometer. J. Am. Soc. Mass Spectrom. 2002, 8, 1396-1406. (b) Polfer, N. C.; Haselmann, K. F.; Zubarev, R. A.; Langridge-Smith, P. R. R. Electron Capture Dissociation of Polypeptides Using a 3 Tesla Fourier Transform Ion Cyclotron Resonance Mass Spectrometer. Rapid Commun. Mass Spectrom. 2002, 16, 936-943. (c) Iavarone, A. T.; Paech, K.; Williams, E. R. Effects of Charge State and Cationizing Agent on the Electron Capture Dissociation of a Peptide. Anal. Chem. 2004, 76, 2231-2238.

57. (a) Vaisar, T.; Gatlin, C. L.; Tureček, F. Oxidation of PeptideCopper Complexes by Alkali Metal Cations in the Gas Phase. J. Am. Chem. Soc. 1996, 118, 5314-5315. (b) Vaisar, T.; Gatlin, C. L.; Tureček, F. Metal-Ligand Redox Reactions in Gas-Phase Quaternary Peptide-Metal Complexes by Electrospray Ionization Mass Spectrometry. Int. J. Mass Spectrom. Ion Processes, 1997, 162, 77-87.

58. Cournoyer, J. J.; Pittman, J. L.; Ivleva, V. B.; Fallows, E.; Waskell, L.; Costello, C. E.; O'Connor, P. B. Differentiation of $\alpha$-versus $\beta$-Aspartic Acid Residues in Peptides by Electron Capture Dissociation. Proceedings of the 52nd ASMS Conference on Mass Spectrometry and Allied Topics; Nashville, TN, May, 2004, A041958.

59. Tureček, F.; unpublished. 